ARTICLE

\title{
mGlu5 receptors and cellular prion protein mediate amyloid- $\beta$-facilitated synaptic long-term depression in vivo
}

Neng-Wei Hu${ }^{1}$, Andrew J. Nicoll ${ }^{2}$, Dainan Zhang ${ }^{1}$, Alexandra J. Mably ${ }^{3}$, Tiernan O'Malley ${ }^{3}$, Silvia A. Purro ${ }^{2}$, Cassandra Terry ${ }^{2}$, John Collinge ${ }^{2}$, Dominic M. Walsh ${ }^{3} \&$ Michael J. Rowan ${ }^{1}$

NMDA-type glutamate receptors (NMDARs) are currently regarded as paramount in the potent and selective disruption of synaptic plasticity by Alzheimer's disease amyloid $\beta$-protein $(A \beta)$. Non-NMDAR mechanisms remain relatively unexplored. Here we describe how $A \beta$ facilitates NMDAR-independent long-term depression of synaptic transmission in the hippocampus in vivo. Synthetic $A \beta$ and $A \beta$ in soluble extracts of Alzheimer's disease brain usurp endogenous acetylcholine muscarinic receptor-dependent long-term depression, to enable long-term depression that required metabotropic glutamate-5 receptors (mGlu5Rs). We also find that mGlu5Rs are essential for $A \beta$-mediated inhibition of NMDAR-dependent long-term potentiation in vivo. Blocking $A \beta$ binding to cellular prion protein with antibodies prevents the facilitation of long-term depression. Our findings uncover an overarching role for $A \beta$-PrPC-mGlu5R interplay in mediating both LTD facilitation and LTP inhibition, encompassing NMDAR-mediated processes that were previously considered primary.

\footnotetext{
${ }^{1}$ Department of Pharmacology and Therapeutics, and Trinity College Institute of Neuroscience, Biotechnology Building, Trinity College Dublin, Dublin 2, Ireland. ${ }^{2}$ Medical Research Council Prion Unit and Department of Neurodegenerative Disease, UCL Institute of Neurology, Queen Square, London WC1N 3BG, UK. ${ }^{3}$ Laboratory for Neurodegenerative Research, Center for Neurologic Diseases, Brigham \& Women's Hospital, Harvard Institute of Medicine, 77 Avenue Louis Pasteur, Boston, Massachusetts 02115, USA. Correspondence and requests for materials should be addressed to M.J.R. (email: mrowan@tcd.ie).
} 
ncreasing our understanding of how amyloid- $\beta$ protein $(A \beta)$ causes synaptic dysfunction should provide new means of therapeutically targeting early Alzheimer's disease $(\mathrm{AD})^{1}$. It is now well established that $\mathrm{A} \beta$ has rapid, profound and selective disruptive effects on synaptic plasticity of excitatory synaptic transmission in vulnerable brain regions, including the hippocampus ${ }^{2}$. In addition to causing strong inhibition of longterm potentiation (LTP), A $\beta$ has been reported to enhance longterm depression (LTD). Most research has focused on the actions of $A \beta$ on forms of LTP and LTD that require NMDA-type glutamate receptors (NMDARs) ${ }^{3-6}$. Indeed, as NMDARdependent LTP is likely to underlie synaptic memory mechanisms ${ }^{7}$, the inhibition of this form of LTP by A $\beta$ is highly congruent with the ability of $A \beta$ to impair learning and memory ${ }^{8,9}$. Somewhat similarly, excessive enhancement of LTD that requires NMDARs can cause memory retrieval deficits ${ }^{10,11}$. Remarkably, the disruption of NMDAR-dependent synaptic plasticity by $A \beta$ is itself mediated through NMDARs, in particular, those containing the GluN2B subunit ${ }^{12-15}$.

In contrast, little is known about how $A \beta$ affects forms of synaptic plasticity that do not require NMDARs. Whereas $A \beta$ potently inhibits acetylcholine-induced $\mathrm{LTP}^{16}$, NMDARindependent LTP induced by strong high-frequency conditioning stimulation (HFS) appears to be resistant to disturbance by $\mathrm{A} \beta^{17}$ in the hippocampus in vitro. Recently, $A \beta$ was reported to enable an NMDAR-independent LTD that was blocked by metabotropic glutamate-5 receptor (mGlu5R) antagonists in hippocampal slices $^{5,8}$. Indeed, synaptically evoked activation of mGlu5R or other similar G-protein coupled receptors including M1 muscarinic acetylcholine receptors (mAChRs) can induce LTD that does not require NMDARs ${ }^{11,18-20}$. Moreover, mAChRdependent LTD has been proposed to underlie visual recognition memory in the perirhinal cortex ${ }^{21}$ and to provide a neurophysiological basis for preserved memory function in the ageing hippocampus ${ }^{22}$. Considering the early vulnerability of cholinergic pathways and related signalling in $\mathrm{AD}^{23,24}$, we hypothesize that $A \beta$ would inhibit mAChR-dependent LTD.

Remarkably, in vivo exposure to low-dose $A \beta$ facilitated an NMDAR-independent form of LTD but does not appear to affect mAChR-dependent LTD. This A $\beta$-facilitated LTD is found to be mGlu5R-dependent. Moreover, A $\beta$-mediated inhibition of LTP is also dependent on metabotropic glutamate-5 receptors (mGlu5Rs), indicating a key overarching role of this glutamate receptor subtype. We also discover that cellular $\operatorname{PrP}$, a receptor for certain synaptotoxic $A \beta$ assemblies ${ }^{25,26}$, is necessary for $A \beta$ to facilitate LTD. These data are strongly congruent with recent molecular evidence that $\mathrm{A} \beta$ and cellular prion protein $\left(\mathrm{PrP}^{\mathrm{C}}\right)$ form a complex with mGlu5R at the postsynaptic density ${ }^{27}$ and thereby disrupt synaptic plasticity.

\section{Results}

In vivo induction of $\mathrm{mAChR}$-dependent LTD. In order to study the effects of $\mathrm{A} \beta$ on $\mathrm{mAChR}$-dependent LTD in vivo, we a
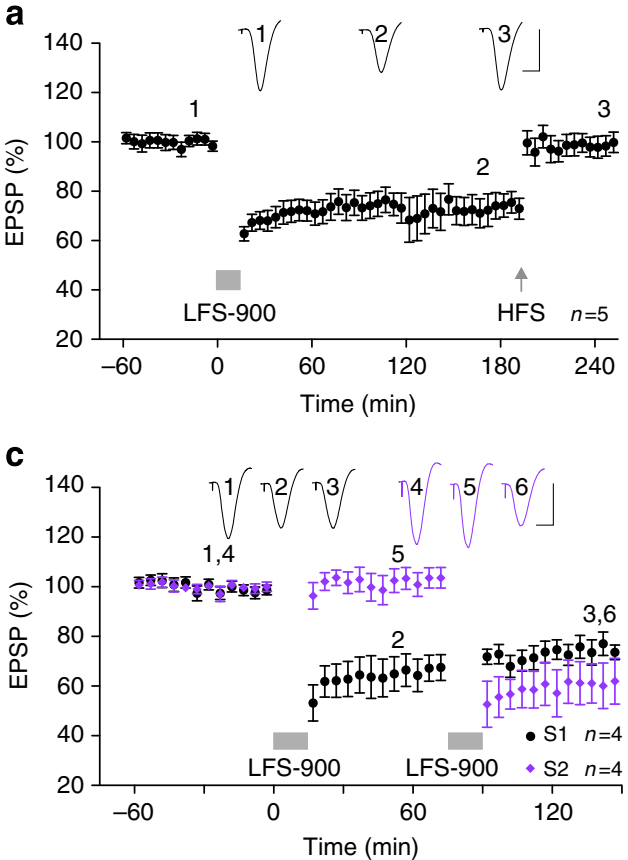

b

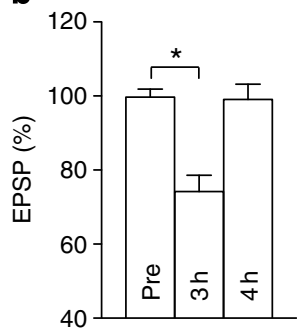

d

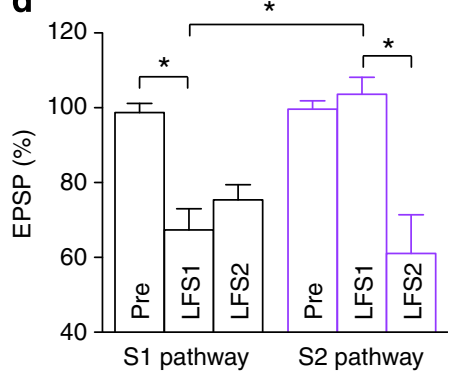

Figure 1 | Low-frequency stimulation induces input-selective and reversible long-term depression at CA3-to-CA1 synapses in vivo. (a,b) Application of strong LFS (horizontal bar, LFS-900; 900 pulses at 1 Hz) induced robust and stable LTD. Three hours after LTD induction, application of high-frequency stimulation (arrow, HFS; $200 \mathrm{~Hz}$ ) induced potentiation of synaptic transmission such that LTD was completely reversed. As summarized in (b), the EPSP decreased to $74.2 \pm 3.9 \%$, at $3 \mathrm{~h}$ post LFS $(3 \mathrm{~h}), n=5, P<0.05$ compared with pre-LFS baseline (Pre); one-way ANOVA-Tukey. At $1 \mathrm{~h}$ post HFS ( $4 \mathrm{~h}$ ) the EPSP reverted to $99.1 \pm 3.7 \%, n=5, P>0.05$ compared with Pre; $P<0.05$ compared with LFS). (c,d) In four animals, two stimulation electrodes (S1, black and S2, purple) were implanted in different locations in the stratum radiatum to allow independent activation of the Schaffer collateral-commissural pathway. One hour after stable baseline recording from both S1 and S2 pathways, application of LFS-900 to S1 induced LTD in the S1 pathway but not in the S2 pathway. Conversely, $1 \mathrm{~h}$ after the first LFS, a second LFS was applied to S2 pathway that only induced LTD in pathway S2. As summarized in (d) One hour after application of LFS1, the EPSP in pathway S1 decreased to $67.4 \pm 5.6 \%(P<0.05$ compared with Pre; one-way ANOVA-Tukey) but did not change significantly in the S2 pathway (103.6 $\pm 4.5 \%, P>0.05$ compared with Pre; $P<0.05$ compared with S1 pathway; $t$-test). In contrast, $1 \mathrm{~h}$ after application of LFS2, the EPSP was significantly reduced in the S2 pathway $(61.1 \pm 10.4 \%, P<0.05$ compared with Pre) but no further change was seen in the $S 1$ pathway $(75.4 \pm 4.1 \%, P>0.05$ compared with EPSP amplitude pre-LFS2). Values are expressed as \% mean baseline EPSP amplitude \pm s.e.m. Insets show representative EPSP traces at the times indicated. Calibration bars: vertical, $2 \mathrm{mV}$; horizontal, $10 \mathrm{~ms} .{ }^{\star} P<0.05$. 
developed a novel induction protocol that makes use of the reported requirement for high-intensity pulses to ensure robust synaptic ACh release during low-frequency conditioning stimulation (LFS) in the neocortex ${ }^{28}$. We found that application of strong LFS, consisting of 900 high-intensity pulses at $1 \mathrm{~Hz}$ (LFS-900), in the stratum radiatum of anaesthetized rats triggered synaptic LTD that (i) was stable for $\sim 3 \mathrm{~h}$ (Fig. 1a,b), (ii) was readily reversible by HFS (Fig. 1a,b) and (iii) was input specific (Fig. 1c,d).

Consistent with the essential requirement for activation of cholinergic mechanisms in the induction of this form of LTD, LFS-900 failed to induce LTD of synaptic transmission after
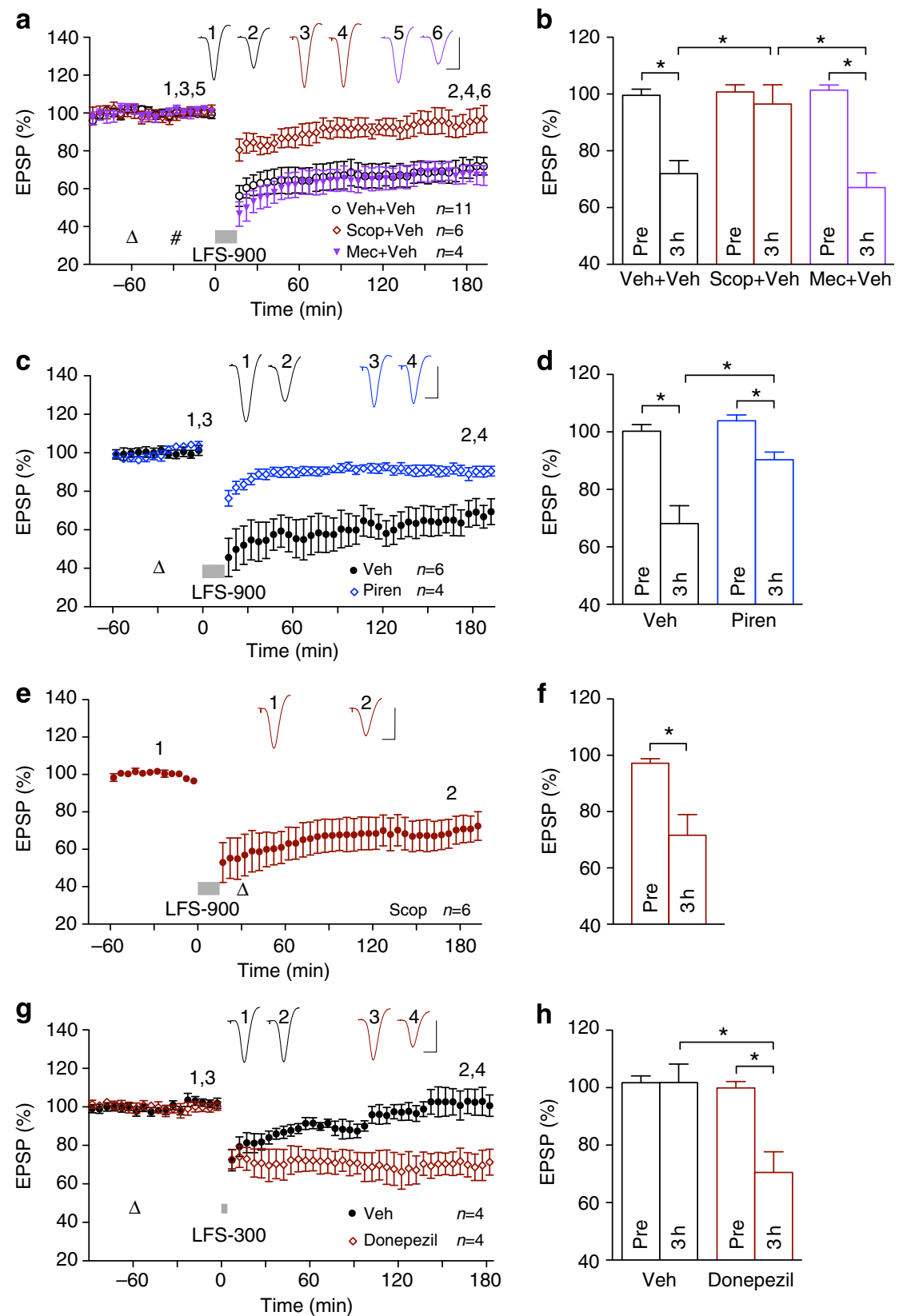

Figure 2 | Muscarinic receptor-dependence of LTD in vivo. (a,b) Systemic injection of scopolamine $\left(0.2 \mathrm{mg} \mathrm{kg}^{-1}\right.$, i.p.), a muscarinic acetylcholine receptor antagonist, completely prevented LFS-induced LTD, whereas application of the nicotinic acetylcholine receptor antagonist mecamylamine ( $5 \mathrm{mg} \mathrm{kg}^{-1}$, i.p.) did not affect LTD induction. Open triangle, i.p.; hash, intracerebroventricular (i.c.v.). As summarized in (b) the EPSP decreased significantly to $72.0 \pm 4.4 \%$ in the vehicle control group and the mecamylamine group $(67.1 \pm 4.9 \%, n=4, P<0.05$ compared with Pre, $P>0.05$ compared with vehicle) but not in the scopolamine group ( $96.5 \pm 6.4 \%, n=6, P>0.05$ compared with Pre, $P<0.05$ compared with vehicle); paired $t$ and one-way ANOVA-Tukey. (c,d) LFS-900-induced LTD was also significantly reduced by treatment with the M1-selective mAChR antagonist pirenzepine (triangle, $50 \mathrm{nmol}$ in $5 \mu \mathrm{l})$. As summarized in (d), the EPSP decreased to $67.5 \pm 4.5 \%$ and $90.4 \pm 2.1 \%, n=4$, in vehicle- and pirenzepine-injected animals, respectively $(P<0.05$ compared with Pre and between groups; $t$-test). (e,f) Application of LFS-900 before the injection of scopolamine (triangle, $0.2 \mathrm{mg} \mathrm{kg}^{-1}$, i.p.) induced robust LTD $(71.7 \pm 7.2 \%, n=6, P<0.05$ compared with Pre; paired $t)$. (g,h) The acetylcholinesterase inhibitor donepezil lowered the threshold to induce LTD. (g) The application of weak LFS (bar, LFS-300; 300 high-intensity pulses at $1 \mathrm{~Hz}$ ) induced a transient synaptic depression in vehicle-injected animals (triangle), whereas the same protocol triggered a robust and stable LTD after acute injection of donepezil (1 $\mathrm{mg} \mathrm{kg}^{-1}$, subcutaneously). (h) Veh: $101.8 \pm 6.3 \%$; donepezil: $70.5 \pm 7.1 \%$ at $3 \mathrm{~h}$ after $\mathrm{LFS} .{ }^{\star} P<0.05, t$-test, $n=4$ per group. Values are mean \pm s.e.m. Calibration bars: vertical, $2 \mathrm{mV}$; horizontal, $10 \mathrm{~ms}$. 
pretreatment with the mAChR antagonist scopolamine (Fig. 2a,b). In contrast, the LTD was not dependent on the activation of nicotinic AChRs, the magnitude of LTD being unaffected by injection of the nicotinic AChR antagonist mecamylamine before LFS-900 (Fig. 2a,b). Consistent with a role for the M1 subtype of mAChR in LTD induction ${ }^{19}$, the M1-selective antagonist pirenzepine significantly reduced the magnitude of LTD (Fig. 2c,d). mAChR activation did not appear to be required for LTD maintenance/expression, as injection of scopolamine after the conditioning stimulation, using the same dose that completely prevented LTD induction, did not significantly affect the magnitude of LTD (Fig. 2e,f). Further evidence that physiological release of ACh is a key factor in LTD induction in vivo was the ability of an agent that enhances the effects of endogenously released $\mathrm{ACh}$, the acetylcholinesterase inhibitor donepezil, to lower the threshold of LTD induction. Thus, we found that a relatively weak LFS conditioning protocol, consisting of 300 high-intensity pulses at $1 \mathrm{~Hz}$ (LFS-300) that was
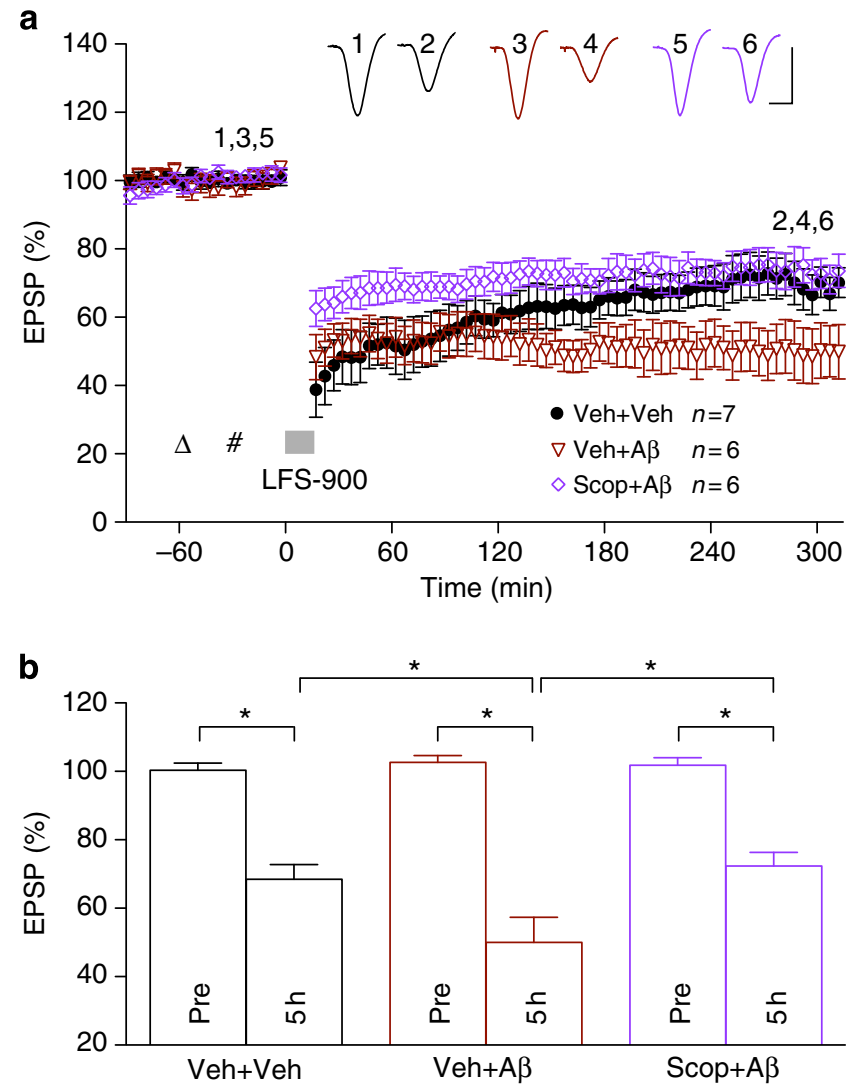

Figure 3 | Intracerebroventricular injection of $\mathbf{A} \boldsymbol{\beta}$ enables an additional LTD that is muscarinic receptor-independent. (a) Intracerebroventricular (hash) injection of 160 pmol soluble $A \beta_{1-42}$ ( $5 \mu$ l of a $32-\mu \mathrm{M}$ solution) $30 \mathrm{~min}$ before the application of LFS-900 did not affect the early phase ( $<2 \mathrm{~h}$ post LFS) but facilitated the late phase ( $3-5 \mathrm{~h}$ post LFS) of LFSinduced LTD. Systemic administration of scopolamine with the dose (open triangle; $0.2 \mathrm{mg} \mathrm{kg}^{-1}$, i.p.) that completely prevented LFS-induced LTD (see Fig. 2a,b) partly attenuated LFS-induced LTD in A $\beta$-treated animals. As summarized in (b), LFS-900 induced LTD measuring $68.5 \pm 4.3 \%$ in controls ( $n=7, P<0.05$ compared with Pre), $50.0 \pm 7.4 \%$ in A $\beta$-pretreated rats $(n=6, P<0.05$ compared with Pre, $P<0.05$ compared with vehicle) and $72.3 \pm 4.0 \%$ in the scopolamine + A $\beta$ group $(n=6, P<0.05$ compared with Pre, $P<0.05$ compared with the $A \beta$-treated group); paired $t$ and one-way ANOVA-Tukey. Values are mean \pm s.e.m. Calibration: vertical, $2 \mathrm{mV}$; horizontal, $10 \mathrm{~ms}$. at or just below the threshold to induce significant LTD in vehicle-pretreated animals, triggered a large and robust LTD that was stable for at least $3 \mathrm{~h}$ in animals pretreated with donepezil (Fig. 2g,h). Moreover, as described below, the induction of this in vivo synaptically evoked mAChR-dependent LTD did not require the activation of NMDA or mGlu5Rs.

Because $A \beta$ can interfere with mAChR-related signalling ${ }^{29}$, we went on to examine the ability of A $\beta$ to disrupt this form of LTD.

A $\beta$ enhances an mAChR-independent form of LTD. We investigated the effects of $\mathrm{A} \beta$ on synaptically evoked mAChRdependent LTD in vivo by the injection of $\mathrm{A} \beta$ into the lateral cerebral ventricle via a cannula. Initially, we used a soluble synthetic $A \beta_{1-42}$ preparation that had been centrifuged to remove any fibril aggregates. We chose a dose $(160 \mathrm{pmol})$ of soluble $\mathrm{A} \beta_{1-42}$ that did not affect baseline synaptic transmission but strongly inhibited NMDAR-dependent LTP, as described below and previously ${ }^{30}$. To our surprise, in animals pre-injected with soluble $A \beta_{1-42}$ the application of LFS-900 triggered an LTD that was more stable than the control LTD induced in the absence of $A \beta$. Thus, LTD induced in the presence of $A \beta$ was stable during the 5-h recording period, whereas control LTD decayed significantly between 3 and $5 \mathrm{~h}$ post LFS (Fig. 3a,b). Although we had hypothesized that mAChR-dependent LTD would be inhibited by $A \beta$, we wondered whether this $A \beta$-facilitated LTD required mAChRs. We therefore pretreated the rats with scopolamine before $A \beta$. In contrast to control LTD, which was completely abrogated by the mAChR antagonist (Fig. 2a,b), the time course and magnitude of LTD was only partly reduced by scopolamine in $A \beta$-treated animals (Fig. 3a,b). These findings indicate that $A \beta$ had enabled an additional LTD that was more stable and independent of mAChRs while at the same time leaving a residual $\mathrm{mAChR}$-dependent LTD relatively unscathed.

We wondered whether this $A \beta$-facilitated additional, $\mathrm{mAChR}$ independent, LTD was due to the ability of $A \beta$ to lower the threshold for LTD induction in vivo. We therefore used the weak LFS conditioning protocol (LFS-300). In addition to our standard soluble $A \beta_{1-42}$ preparation we also tested a preparation of soluble $A \beta_{1-42}$ enriched with protofibrils (Fig. 4). We combined the results obtained with the two synthetic $A \beta_{1-42}$ preparations because there was no quantitative difference in their effects on LTD. The application of weak LFS-300 induced a large and robust

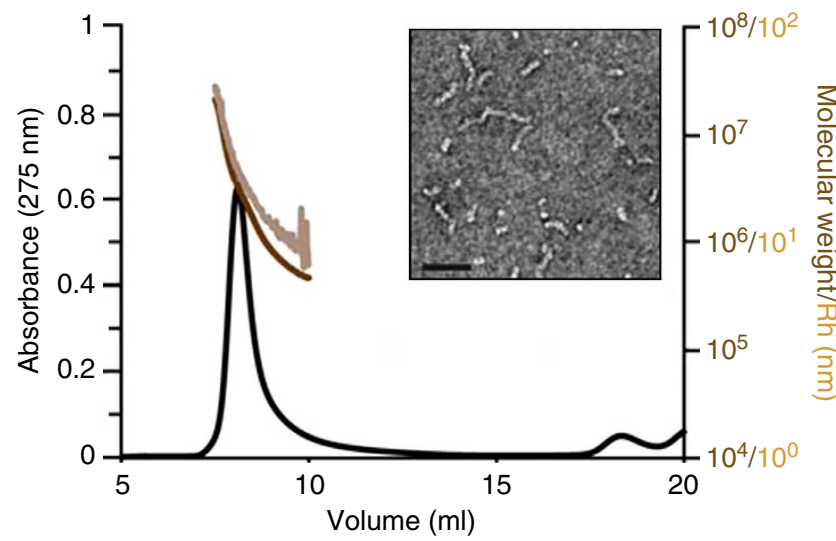

Figure 4 | Characterization of protofibril $\mathbf{A} \boldsymbol{\beta}_{\mathbf{1}-42}$ preparation.

Characterization of $A \beta_{1-42}$ protofibrils by electron microscopy (EM), SEC and quasi-elastic light scattering (QELS) confirm these preparations contain predominantly protofibrillar assemblies of $10-100 \mathrm{~nm}$ in length with molecular weights of $10^{5}-10^{7}$ and hydrodynamic radii of $8-50 \mathrm{~nm}$. Scale bar, $50 \mathrm{~nm}$. 
LTD that was stable for at least $3 \mathrm{~h}$ in animals injected with $\mathrm{A} \beta_{1-42}$ (Fig. 5a,b), but not vehicle or a control, reverse sequence peptide $A \beta_{42-1}$ (Fig. 5a,b). This dose (160 pmol) of $A \beta_{1-42}$ did not affect baseline synaptic transmission (Fig. 5a,b) and consistent with a relatively selective action of $\mathrm{A} \beta$ on the mechanisms underlying LTD induction, the same dose applied after the LFS300 conditioning stimulation failed to facilitate LTD (Fig. 5c,d). Moreover, the LTD induced by weak LFS-300 in the presence of $\mathrm{A} \beta$, like the additional LTD induced by the strong LFS-900 protocol, was also $\mathrm{mAChR}$-independent, not being blocked by scopolamine pretreatment (Fig. 5e,f).

Although synthetic $A \beta$ is most commonly used in studies of synaptic plasticity disruption, it is important to determine whether similar effects are caused by natural $A \beta$. The presence of water-soluble SDS-stable $A \beta$ dimer in post-mortem brain extracts is highly correlated with ante-mortem dementia status ${ }^{31}$ and such $\mathrm{A} \beta$ can inhibit LTP and promote LTD in vitro ${ }^{5,8}$. It is therefore of great interest to assess whether $\mathrm{AD}$ brain-derived $\mathrm{A} \beta$ can also facilitate LTD induction in vivo. Consequently, we tested
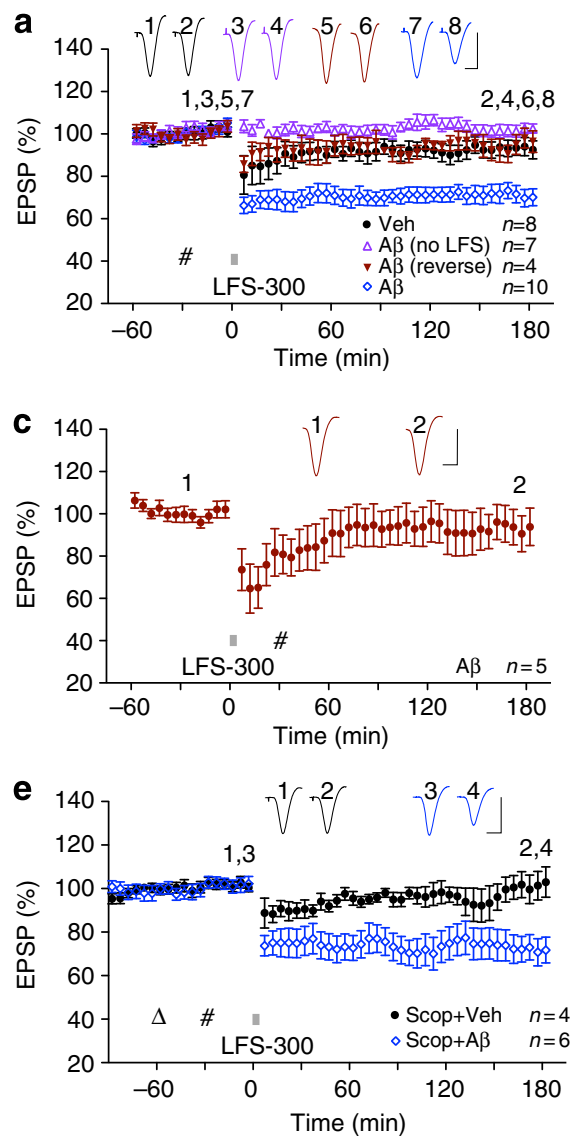

the ability of $\mathrm{A} \beta$ in water-soluble extracts of two different $\mathrm{AD}$ brains to mimic the ability of synthetic $A \beta_{1-42}$ to lower the threshold for LTD induction in vivo. As can be seen from the western blot of one of the AD brain extracts (Fig. 6a), A $\beta$ runs on SDS gel predominantly as either monomer or dimer. These water-soluble SDS-stable species include a wide distribution of assemblies when analysed by size exclusion chromatography (SEC), ranging from monomer to $\geq 70 \mathrm{kDa}$ (ref. 8). Similar to synthetic $A \beta$, the injection of $A \beta$-containing $A D$ brain soluble extract enabled the induction of robust and stable LTD by LFS300 (Fig. 6b,c). Importantly, immunodepletion of $\mathrm{A} \beta$ from the $\mathrm{AD}$ brain sample abrogated its ability to enable LTD induction. This finding indicates that soluble $A \beta$ is responsible for the lowering of the LTD induction threshold by the AD brain extract. Which SDS-stable A $\beta$ assembly is responsible for the facilitation of LTD by AD TBS brain extract remains to be determined.

A $\beta$-facilitated LTD is NMDAR-independent. Because A $\beta$ has been reported to promote NMDAR-dependent LTD $^{5,6}$, we
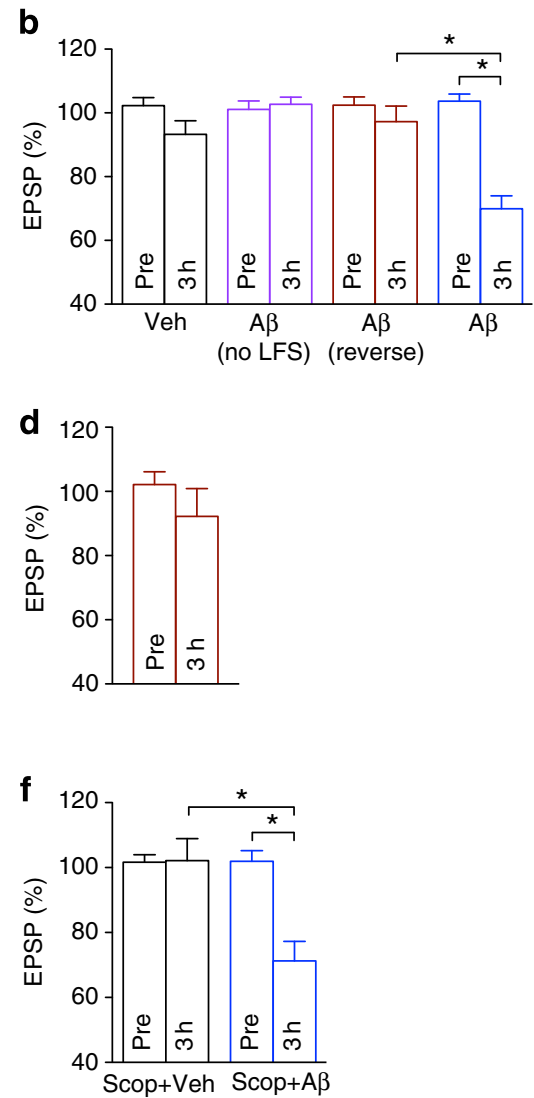

Figure 5 | A $\beta$ facilitates the induction of muscarinic receptor-independent LTD by weak low-frequency stimulation. (a,b) The application of weak LFS (bar, LFS-300; 300 high-intensity pulses at $1 \mathrm{~Hz}$ ) triggered a robust and stable LTD after acute i.c.v. injection (hash) of $160 \mathrm{pmol} A \beta_{1-42}$ but not vehicle or the reverse peptide $A \beta_{42-1}$ ( $A \beta$ reverse). This dose of $A \beta_{1-42}$ did not affect baseline synaptic transmission in the absence of LFS-300 (A $\beta$ no LFS). Data for soluble and protofibril $A \beta$ are combined and some animals had an additional separate i.c.v. injection of $5 \mu$ l vehicle 15 min before $A \beta$. As summarized in (b) at $3 \mathrm{~h}$ the EPSP measured $93.3 \pm 3.6 \%$ in controls $(n=8, P>0.05$ compared with Pre; paired $t), 69.9 \pm 3.8 \%$ in A $\beta$-injected rats $(n=10$, $P<0.05$ compared with Pre and vehicle group; paired $t$ and one-way ANOVA-Tukey) and $97.3 \pm 4.3 \%$ in reverse peptide $(n=4, P>0.05$ compared with Pre). Injection of $A \beta_{1-42}(160$ pmol, i.c.v.) did not affect baseline synaptic transmission (102.6 $\pm 1.6 \%$ at $3 h, n=7, P>0.05$ compared with Pre). (c,d) $A \beta_{1-42}$, when administered $15 \mathrm{~min}$ after LFS-300 did not facilitate LTD. As summarized in (d) the EPSP was not significantly decreased at $3 \mathrm{~h}$ post LFS-300 (92.2 $\pm 8.3 \%, n=5, P>0.05$ compared with Pre; paired $t$ ). (e,f) In animals pretreated with scopolamine at the dose (open triangle; $0.2 \mathrm{mg} k \mathrm{~kg}^{-1}$, i.p.) that completely blocked LFS-induced LTD (see Fig. 2a,b), application of LFS-300 30 min after i.c.v. injection of vehicle did not induce LTD, whereas application of LFS-300 30 min after i.c.v. injection of soluble $A \beta_{1-42}$ induced a robust and stable LTD. As summarized in (f), at $3 \mathrm{~h}$ the EPSP measured $102.2 \pm 6.6 \%$ in the scopolamine + vehicle group $(n=4, P>0.05$ compared with Pre; paired $t)$ and $71.2 \pm 5.8 \%$ in the scopolamine $+A \beta$ group $(n=6, P<0.05$ compared with Pre or scopolamine + vehicle group; $t$-tests). Values are mean \pm s.e.m. Calibration: vertical, $2 \mathrm{mV} ;$ horizontal, $10 \mathrm{~ms}$. 

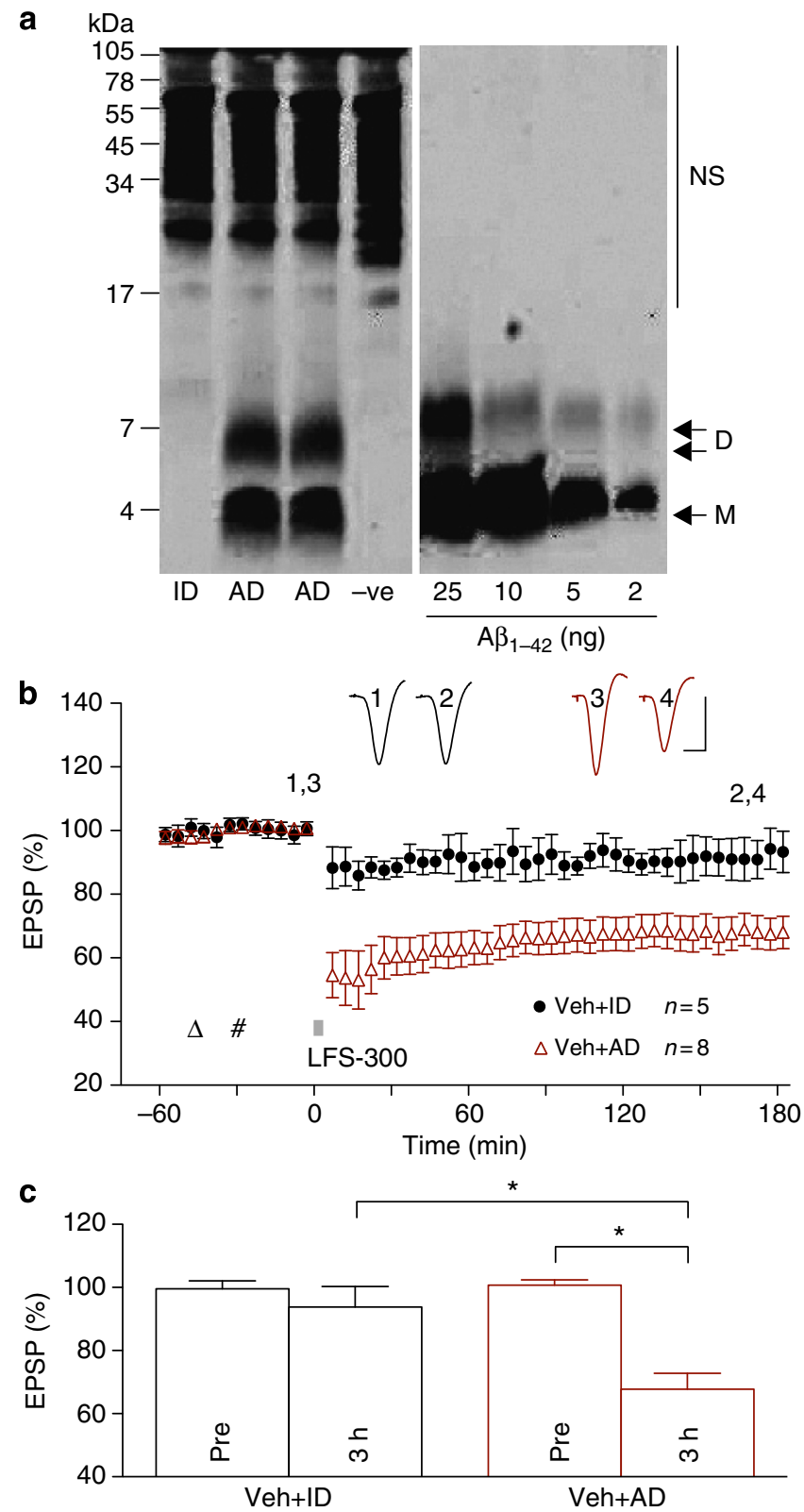

Figure 6 | A $\beta$ in AD brain TBS soluble extract facilitates LTD in vivo.

(a) The TBS extract of AD2 was examined by immunoprecipitation/western blot as described in the Methods. The second and third lanes of the WB show duplicate samples of the buffer-exchanged AD2 extract that contained $A \beta$ monomer (M) and SDS-stable A $\beta$ dimers (D). The first lane shows that the immunodepleted sample had been effectively depleted of all detectable $A \beta$. Known amounts of synthetic $A \beta_{1-42}$ were electrophoresed on the same gel to allow estimation of $A \beta$ content in the test samples ( $\sim 8.8 \mathrm{ng} \mathrm{ml}^{-1}$ and $5.6 \mathrm{ng} \mathrm{ml}^{-1} \mathrm{~A} \beta$ monomer and dimer, respectively). Molecular weight standards are indicated on the left and are given in $\mathrm{kDa}$. Cross-reactive immunoglobulin-derived proteins that were detected when TBS buffer was immunoprecipitated are indicated (NS). (b,c) Similar to soluble synthetic $A \beta_{1-42}$, acute i.c.v. injection of unmanipulated TBS extract of AD brain $(A D, 5 \mu \mathrm{l})$ also enabled the induction of robust and persistent LTD by the weak LFS-300 protocol. In contrast, the same extract of AD brain that had been immunodepleted of $A \beta$ using a polyclonal anti-A $\beta$ antibody (ID) did not enable the induction of LTD by LFS-300. Triangle: Vehicle; hash: AD or ID. As summarized in (c) at $3 \mathrm{~h}$ the EPSP measured $67.8 \pm 4.8 \%$ in the AD group $(n=8, P<0.05$ compared with Pre; paired $t)$ and $93.8 \pm 6.3 \%$ in the ID group $(n=5, P>0.05$ compared with Pre; $P<0.05$ compared with AD group;

$t$-test). Values are mean \pm s.e.m. Calibration: vertical, $2 \mathrm{mV}$; horizontal, $10 \mathrm{~ms}$. postulated that activation of NMDARs in the presence of $A \beta$ may bypass the need for mAChRs in the induction of LTD in vivo. Contrary to our prediction, the NMDAR antagonist CPP, at a dose $\left(10 \mathrm{mg} \mathrm{kg}^{-1}\right.$, intraperitoneal (i.p.)) that completely blocks HFS-induced LTP ${ }^{32}$, did not affect the induction of LTD by LFS300 in the presence of soluble $A \beta_{1-42}$ (Fig. 7a,b). As CPP is a competitive antagonist and NMDARs containing GluN2B subunits are particularly implicated in $A \beta$-mediated synaptic plasticity disruption ${ }^{12-15}$, we also tested the GluN2B-selective negative allosteric modulator Ro 25-6981 (ref. 33). Using a dose $\left(6 \mathrm{mg} \mathrm{kg}^{-1}\right.$, i.p.) that prevents $\mathrm{A} \beta$-mediated inhibition of $\mathrm{LTP}^{12}$, Ro 25-6981 had no effect on the facilitation of LTD by A $\beta$ (Fig. 7c,d). We concluded that like control LTD induced by LFS-900 (Fig. 7e,f), A $\beta$-facilitated LTD induced by LFS-300 is NMDAR-independent.

HFS-induced de-depression of LTD is NMDAR-dependent. In the light of the contrasting findings regarding the involvement of NMDARs in the disruptive effects of $A \beta$ on LFS-induced LTD (present study) and HFS-induced LTP ${ }^{12-15}$, we also examined the effect of $A \beta$ on another form of synaptic plasticity, HFS-induced de-depression. De-depression is the persistent reversal of LTD by conditioning stimulation and is believed to be an essential component of bidirectional synaptic plasticity ${ }^{34,35}$. Although the induction of control LTD did not require activation of NMDARs, the reversal of this LTD by HFS in vivo was NMDAR-dependent. Thus, whereas the NMDAR antagonist CPP did not affect control LTD induced by LFS-900, it completely prevented the reversal of this mAChR-dependent LTD by HFS conditioning stimulation (Fig. 7e,f). To our surprise, HFS-induced de-depression was not prevented by $A \beta$. Thus, HFS rapidly and persistently reversed A $\beta$-facilitated LTD (Fig. 7a,b). Moreover, HFS-induced de-depression of $A \beta$-facilitated LTD, like the persistent reversal of control LTD, was NMDAR-dependent, being abrogated in animals pretreated with CPP (Fig. 7a,b). This indicates that HFSinduced NMDAR-dependent de-depression is resistant to $A \beta$, unlike HFS-induced NMDAR-dependent LTP, as described previously $^{3,4}$ and below. This lack of effect of $A \beta$ on NMDARdependent de-depression, taken together with the inability of NMDAR antagonists to prevent the facilitation of LTD by A $\beta$, underlines the potential importance of non-NMDAR mechanisms in mediating the synaptic plasticity disrupting effects of $\mathrm{A} \beta$ in vivo.

Aß-facilitated LTD is mGlu5R-dependent. Apart from NMDARs, metabotropic glutamate receptors, in particular the mGlu5R subtype, have been implicated in the synaptic plasticity disrupting actions of $\mathrm{A} \beta$ in vitro ${ }^{5,8,36}$. Bearing in mind the apparently differential roles of NMDARs in the effects of $A \beta$ on different forms of synaptic plasticity, next we assessed the involvement of mGlu5R in both $A \beta$-mediated inhibition of LTP as well as $\mathrm{A} \beta$-facilitated LTD in vivo. Remarkably, systemic administration of the selective mGlu5R antagonist (negative allosteric modulator) MTEP prevented both of these disruptive actions of A $\beta$ without affecting either control LTP or control LTD. Thus, in animals administered with MTEP before intracerebroventricular (i.c.v.). injection of either synthetic or $\mathrm{AD}$ brain-derived $\mathrm{A} \beta$ the application of LFS-300 failed to induce LTD (Fig. 8a-d). Importantly, the same dose of MTEP had no effect on control LTD induced by LFS-900 (Fig. 8e,f), indicating that whereas $A \beta$-facilitated LTD is mGlu5R-dependent, this was not the case for the control mAChR-dependent LTD. Somewhat similarly, whereas $\mathrm{A} \beta_{1-42}$ strongly inhibited LTP in vehiclepretreated animals, an identical HFS-triggered robust LTP in animals injected with MTEP followed by A $\beta$ (Fig. 8g,h). These 

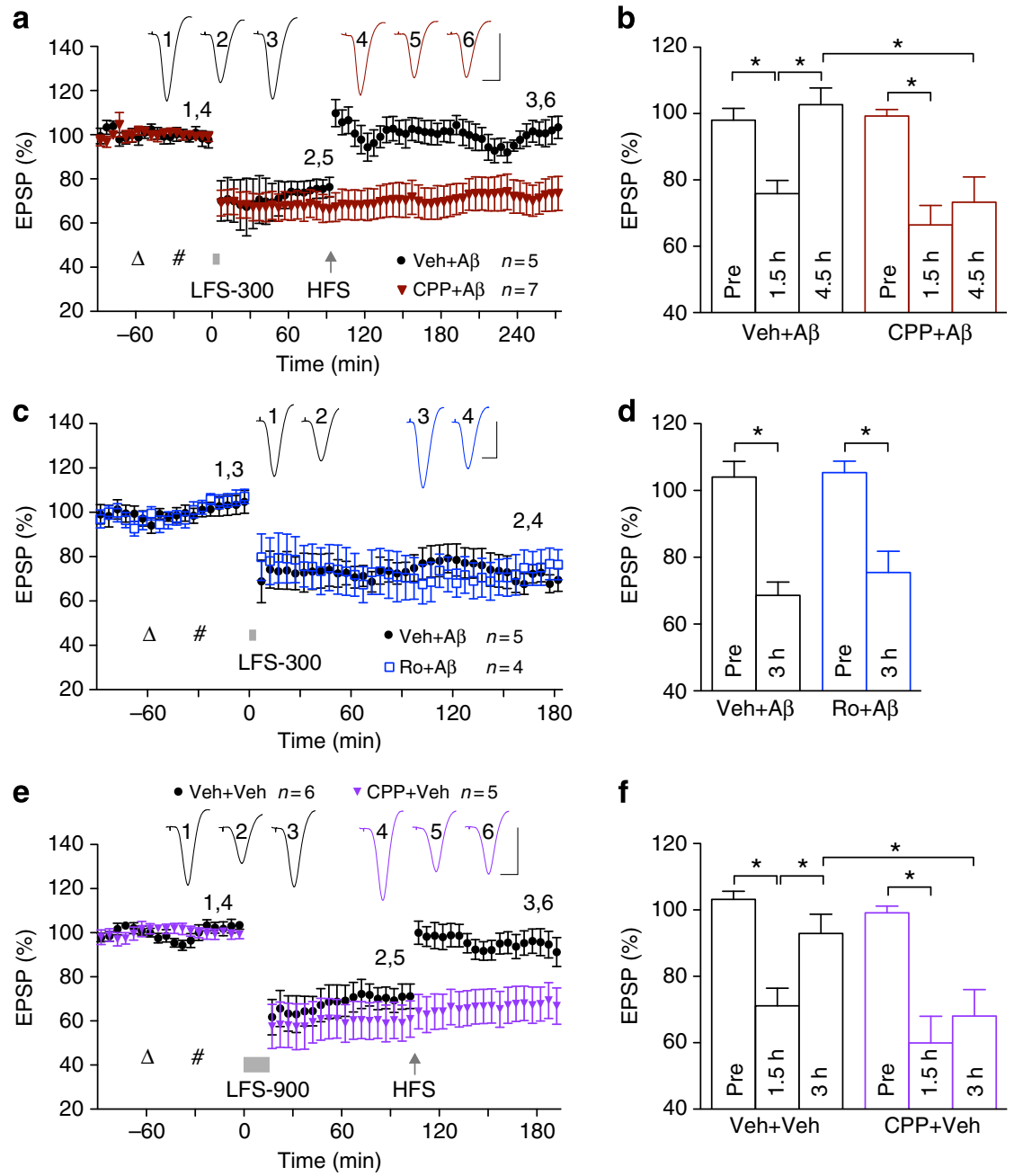

Figure 7 | NMDAR antagonists do not affect LTD but prevent LTD reversal. (a,b) LFS-300 (bar) after A $\beta_{1-42}$ (i.c.v., hash) triggered LTD that was reversed by HFS. The competitive antagonist CPP (open triangle; $10 \mathrm{mg} \mathrm{kg}^{-1}$, i.p.) did not affect A $\beta$-facilitated LTD but prevented de-depression. (b) Thus LTD at $1.5 \mathrm{~h}$ measured $75.9 \pm 4.0 \%(n=5)$ and $66.5 \pm 5.8 \%(n=7)$ in the vehicle $+\mathrm{A} \beta$ group and CPP $+\mathrm{A} \beta$ group, respectively $(P<0.05$ compared with Pre, one-way ANOVA-Tukey, $P>0.05$ between groups; two-way ANOVA followed by unpaired $t$ ). The EPSP measured $102.7 \pm 5.1 \%$ in the vehicle $+A \beta$ group (at $3 \mathrm{~h}, P>0.05$ compared with Pre and $P<0.05$ compared with $1.5 \mathrm{~h}$ post LFS) and $73.3 \pm 7.6 \%$ in the CPP $+\mathrm{A} \beta$ group $(P>0.05$ compared $1.5 \mathrm{~h}$ post $\mathrm{LFS}$, $P<0.05$ compared with the vehicle $+A \beta$ group). (c,d) Injection of Ro 25-6981 (open triangle; $6 \mathrm{mg} \mathrm{kg}-1$, i.p.), a negative allosteric modulator of GluN2B-containing NMDARs, did not prevent $A \beta_{1-42}$ (hash)-facilitated LTD $(75.5 \pm 6.3 \%$ at $3 \mathrm{~h}, n=5, P<0.05$ compared with Pre, $P>0.05$ compared with $68.6 \pm 4.0 \%$ in the vehicle $+A \beta$ injection group; $t$-tests). (e,f) Control LTD, induced by LFS-900 (bar) was also reversed by HFS (arrow). CPP failed to significantly affect control LTD, but blocked de-depression. (f) Thus, LFS-900 induced LTD in controls (71.1 $\pm 5.3 \%$ at $1.5 \mathrm{~h}, n=6, P<0.05$ compared with Pre; one-way ANOVA-Tukey) and CPP-injected rats $(59.9 \pm 8.0 \%, n=5, P<0.05$ compared with Pre, $P>0.05$ compared with vehicle; two-way ANOVA followed by unpaired $t$ ). The EPSP measured $92.9 \pm 5.8 \%$ at 90 min in controls ( $P>0.05$ compared with Pre) and $68.0 \pm 8.0 \%$ in the CPP group $(P>0.05$ compared with $1.5 \mathrm{~h}$ post LFS, $P<0.05$ compared with vehicle). Values are mean \pm s.e.m. Calibration: vertical, $2 \mathrm{mV} ;$ horizontal, $10 \mathrm{~ms}$.

findings strongly indicate that $\mathrm{A} \beta$ enables LTD induction in vivo with an essential role of mGlu5, bypassing a requirement for activation of muscarinic ACh receptors. Moreover as MTEP prevented A $\beta$ 's effects on both LTP and LTD, mGlu5Rs appear to be more pivotal to the synaptic plasticity disrupting actions of $A \beta$ than NMDARs.

Cellular prion protein mediates A $\beta$-facilitated LTD. The question arises as to whether or not the facilitation of LTD by A $\beta$ shares other common mechanisms with LTP inhibition by A $\beta$. A $\beta$ oligomers can bind very potently and selectively to cellular prion protein especially in a region that encompassed the aminoacid sequence $95-105$, and thereby mediate inhibition of LTP by synthetic $A \beta_{1-42}$ (ref. 25). The disease relevance of this finding is underscored by the $\mathrm{PrP}^{\mathrm{C}}$-dependence of the inhibition of LTP by $\mathrm{A} \beta$ oligomer-containing soluble extract of $\mathrm{AD}$ brain $^{37}$. We examined the role of $\operatorname{PrP}^{C}$ in mediating the facilitation of LTD by $\mathrm{AD}$ brain $\mathrm{A} \beta$ and synthetic $\mathrm{A} \beta_{1-42}$ using monoclonal antibodies to $\operatorname{Pr} \mathrm{P}^{\mathrm{C}}$. We started with the previously characterized anti-PrPC antibody 6D11, with an epitope that falls within the amino-acid 93-109 sequence, thereby preventing $A \beta_{1-42}$ oligomer binding and inhibition of $\mathrm{LTP}^{25}$. Pretreatment with $6 \mathrm{D} 11$ completely prevented the facilitation of LTD by A $\beta$-containing soluble AD brain extract (Fig. 9a,b). In order to further explore the role of $\operatorname{PrP}^{\mathrm{C}}$, we compared the effect of two other high-affinity anti$\mathrm{PrP}^{\mathrm{C}}$ antibodies (Fig. 9c,d). ICSM18, an antibody directed to helix-1 of $\operatorname{PrP}^{\mathrm{C}}$, is known to inhibit $\mathrm{A} \beta$ binding to $\operatorname{PrP}^{\mathrm{C}}$ and to prevent the LTP disrupting effect of AD brain extracts ${ }^{37}$. ICSM41 is an antibody to the structured region of $\mathrm{PrP}^{\mathrm{C}}$ with an undefined 

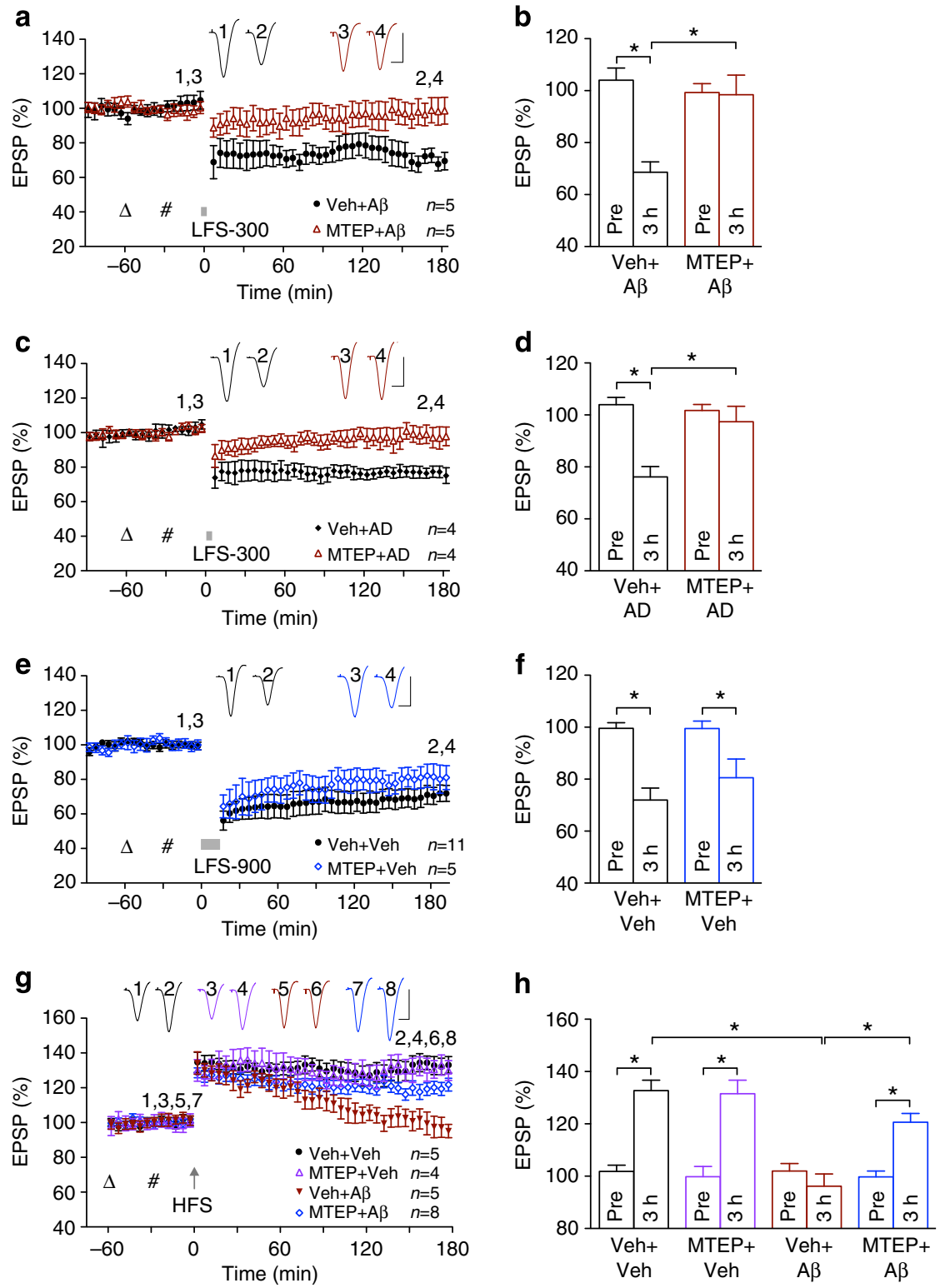

Figure 8 | mGlu5R-dependence of A $\beta$-mediated disruption of both LTD and LTP but not control LTD or control LTP. (a,b) Systemic administration of the selective mGlu5R antagonist MTEP (open triangle; $3 \mathrm{mg} \mathrm{kg}^{-1}$, i.p.) completely prevented the induction of LTD by LFS-300 (bar) in animals injected i.c.v. with soluble $A \beta_{1-42}$ (hash) $(68.6 \pm 4.0 \%$ in the vehicle $+A \beta$ group, $n=5, P<0.05$ compared with Pre, and compared with $98.4 \pm 7.6 \%$ in the $M T E P+A \beta$ group, $n=5, P>0.05$ compared with Pre; $t$-tests). (c,d) Similarly, MTEP completely prevented the induction of LTD in animals injected with A $\beta$-containing AD brain extract. As summarized in (d) the EPSP measured $76.2 \pm 3.6 \%$ in the vehicle + AD group, $n=4,(P<0.05$ compared with Pre, and compared with $97.4 \pm 5.6 \%$ in the MTEP + AD group, $n=4, P>0.05$ compared with Pre; $t$-tests). (e,f) In contrast, the same dose of MTEP that prevented A $\beta$-facilitated LTD failed to significantly affect control LTD induced by LFS-900 (72.0 $\pm 4.4 \%$ in the vehicle + vehicle group, $n=11, P<0.05$ compared with Pre, and $P>0.05$ compared with $80.6 \pm 7.2 \%$ in the MTEP + vehicle group, $n=5, P<0.05$ compared with Pre; $t$-tests). (g,h) i.c.v. injection of soluble $\mathrm{A} \beta_{1-42}$ (hash), at the dose that facilitated LTD, blocked LTP completely at $3 \mathrm{~h}$ post HFS. Although systemic administration of MTEP ( $\left.3 \mathrm{mg} \mathrm{kg}{ }^{-1}\right)$ did not affect HFS-induced control LTP, it prevented A $\beta$-mediated impairment of LTP. As summarized in (h), HFS induced significant $(P<0.05$ compared with Pre; paired $t)$ LTP in the vehicle control group $(132.7 \pm 4.0 \%, n=5)$, MTEP + vehicle group $(131.5 \pm 5.2 \%, n=4)$ and MTEP $+A \beta$ group $(120.6 \pm 3.4 \%, n=8)$, but not in the vehicle $+A \beta$ group $(96.2 \pm 4.7 \%, n=5)$, which was significantly different from the other groups (one-way ANOVA-Tukey). Values are mean \pm s.e.m. Calibration: vertical, $2 \mathrm{mV}$; horizontal, $10 \mathrm{~ms}$.

epitope that does not map to the A $\beta$-binding region ${ }^{38,39}$. Although ICSM41 binds with similar high affinity to recombinant $\mathrm{PrPC}^{\mathrm{C}}$ as $\mathrm{ICSM} 18\left(\mathrm{IC}_{50}: 0.41 \pm 0.04\right.$ and $0.3 \pm 0.1 \mathrm{nM}$, respectively, $n=9$, mean \pm s.e.m.), unlike ICSM18, ICSM41 did not prevent $A \beta_{1-42}$ protofibril binding to $\operatorname{PrP}^{\mathrm{C}}$ (Fig. 10b,c). Consistent with the differential ability of these two antibodies to prevent $\mathrm{A} \beta_{1-42}$ binding to $\operatorname{PrP}^{\mathrm{C}}$, ICSM18 abrogated the facilitation of LTD by soluble AD brain extract, whereas the same dose of ICSM41 had no effect (Fig. 9c,d). These findings provide strong evidence that $\mathrm{PrP}^{\mathrm{C}}$ is required for the enablement of LTD by the most disease relevant form of soluble $A \beta, A \beta$ from AD brain. We also tested the ability of ICSM18 to prevent the facilitation of LTD by synthetic $A \beta_{1-42}$. A $\beta$ from water-soluble extracts of $\mathrm{AD}$ brain contain a mixture of high- and lowmolecular weight components ${ }^{8}$, some of which bind to $\mathrm{PrP}^{\mathrm{C}}$ with high affinity ${ }^{40,41}$. In the case of synthetic $A \beta$, protofibrillar 
a

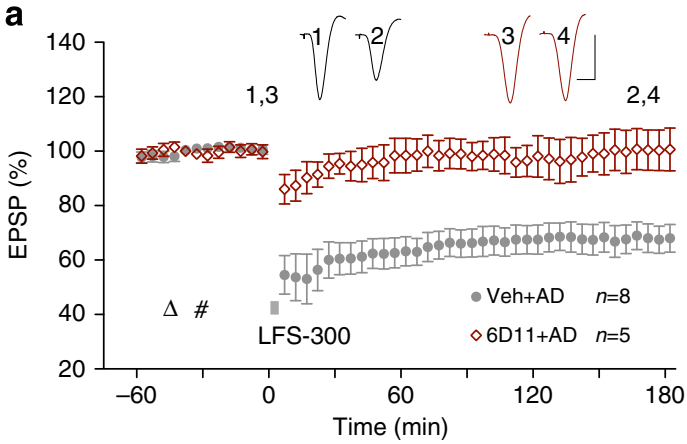

C
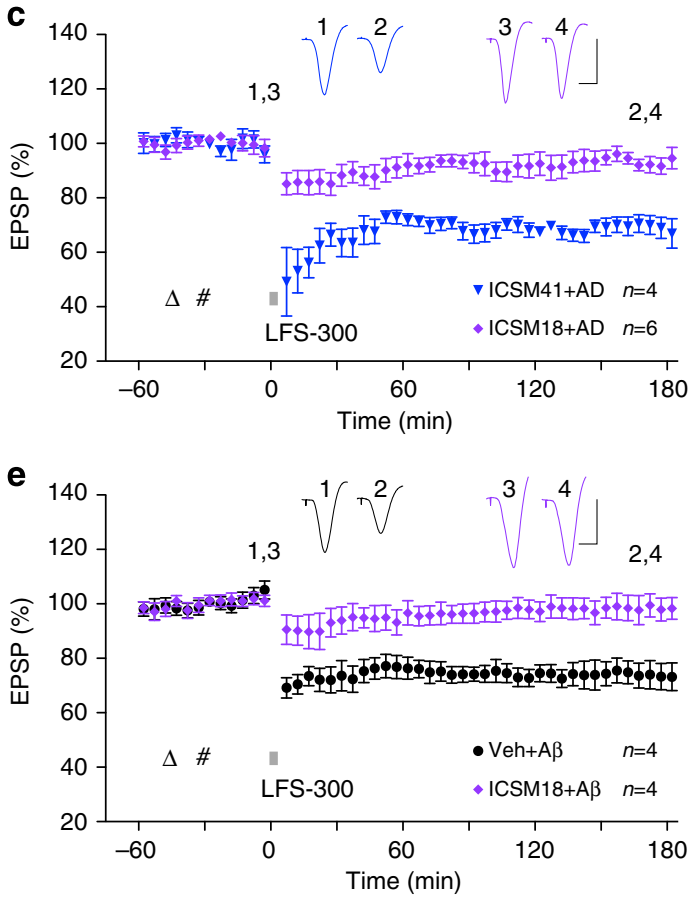

b

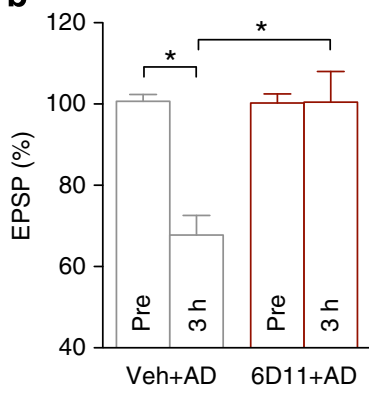

d

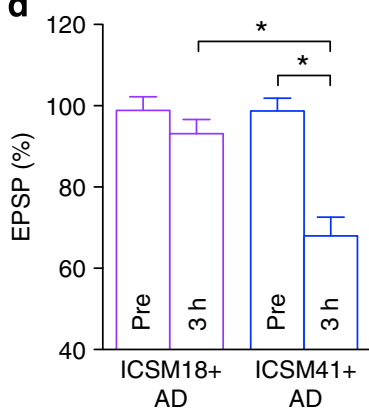

f

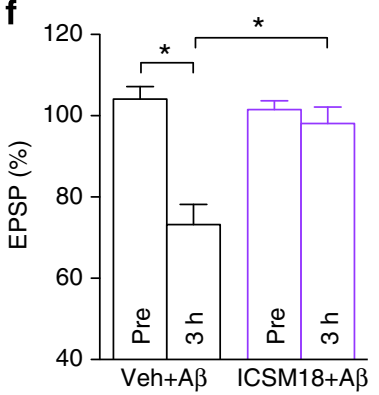

Figure 9 | Cellular prion protein is necessary for the facilitation of LTD by Aßק. (a,b) Injection of 6D11 (triangle; $20 \mu \mathrm{g}$ in $10 \mu$ l, i.c.v.), an antibody directed to the main binding site of $A \beta$ on $\operatorname{Pr} P C, 15$ min before the injection of soluble $A \beta$-containing $A D$ brain extract (hash) prevented the facilitation of LTD (interleaved experiments with vehicle $+A D$, from Fig. 5). As summarized in (b) at $3 \mathrm{~h}$ post LFS the EPSP measured $100.5 \pm 7.5 \%, n=5$, in the $6 \mathrm{D} 11+\mathrm{AD}$ group $(P>0.05$ compared with Pre; $P<0.05$ compared with the vehicle $+A D$ group; $t$-test). (c,d) Whereas ICSM18 (30 $\mu$ g) prevented the facilitation of LTD by AD brain extract, the same dose of ICSM41 was ineffective. As summarized in (d) the EPSP measured $93.1 \pm 2.9 \%, n=6$, in the ICSM18 + AD group ( $P>0.05$ compared with Pre and $P<0.05$ compared with $68.0 \pm 4.2 \%, n=4$, in the ICSM41+AD group; $t$-test). (e,f) ICSM18 $(3.75 \mu \mathrm{g})$ also prevented the facilitation of LTD by protofibril $A \beta_{1-42}$. As summarized in (f) the EPSP measured $98.1 \pm 3.7 \%$ at $3 \mathrm{~h}$ post LFS in the ICSM18 $+A \beta_{1-42}$ group ( $P>0.05$ compared with Pre, $n=4$; and $P<0.05$ compared with $73.2 \pm 4.5 \%, n=4$, in the vehicle $+A \beta_{1-42}$ group; $t$-test). Values are mean \pm s.e.m. Insets show representative EPSP traces at the times indicated. Calibration: vertical, $2 \mathrm{mV}$; horizontal, $10 \mathrm{~ms}$.

assemblies bind most avidly to $\operatorname{PrP}^{\mathrm{C}}$ (ref. 26) (see also Fig. 10a). We tested an eightfold lower dose of ICSM18 in this study because we found that ICSM18 bound to N2A cells, which express glycosylated mature $\operatorname{PrP}^{\mathrm{C}}$, with an approximately eightfold higher affinity than ICSM41 $\left(\mathrm{XC}_{50} 4 \pm 1\right.$ and $33 \pm 7 \mathrm{nM}$, respectively) (Fig. 10d). We found that this dose of ICSM18 completely abrogated the facilitation of LTD by protofibril $A \beta_{1-42}$ (Fig. 9e,f). On the basis of the present and our previous ${ }^{37}$ findings, $\mathrm{PrP}^{\mathrm{C}}$ appears to be a key site of binding and action for $A \beta$-mediated disruption of both NMDARdependent and independent synaptic plasticity in vivo.

\section{Discussion}

We describe here for the first time the in vivo induction by synaptic stimulation of an mAChR-dependent homosynaptic
LTD. The induction of mAChR-dependent LTD does not require NMDA or mGlu5R activation. Moreover, both chemically synthesized and human brain-derived $A \beta$ enhanced synaptically induced LTD in vivo. Remarkably, in A $\beta$-treated animals the additional LTD does not require mAChRs, leaving mAChRdependent LTD relatively intact. However, like mAChR-dependent LTD, the A $\beta$-facilitated LTD is NMDAR-independent. We found evidence that mGlu5R activation usurps the requirement for mAChRs to enable LTD induction via a process dependent on $\operatorname{PrP}^{\mathrm{C}}$. Furthermore, $\mathrm{A} \beta$-mediated inhibition of LTP also requires mGlu5R and $\operatorname{PrP}^{\mathrm{C}}$, placing $\mathrm{A} \beta-\mathrm{PrP}^{\mathrm{C}}-\mathrm{mGlu} \mathrm{R}$ interactions central to the synaptic plasticity disrupting actions of $A \beta$ in vivo.

LTD that requires $\mathrm{MAChR}$ activation has been proposed to be essential for certain forms of learning ${ }^{21}$, and the preservation of mAChR-dependent hippocampal LTD as animals age may be critical for maintaining cognitive performance ${ }^{22}$. The apparent 
a

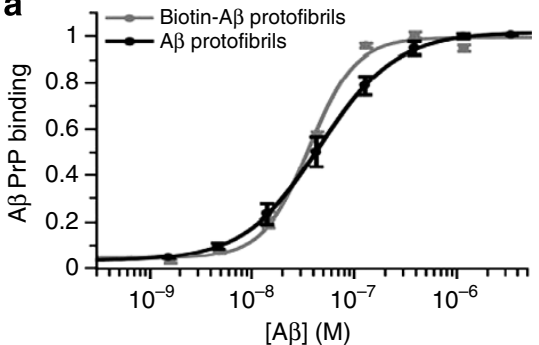

C

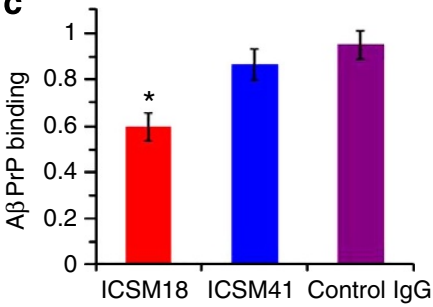

b
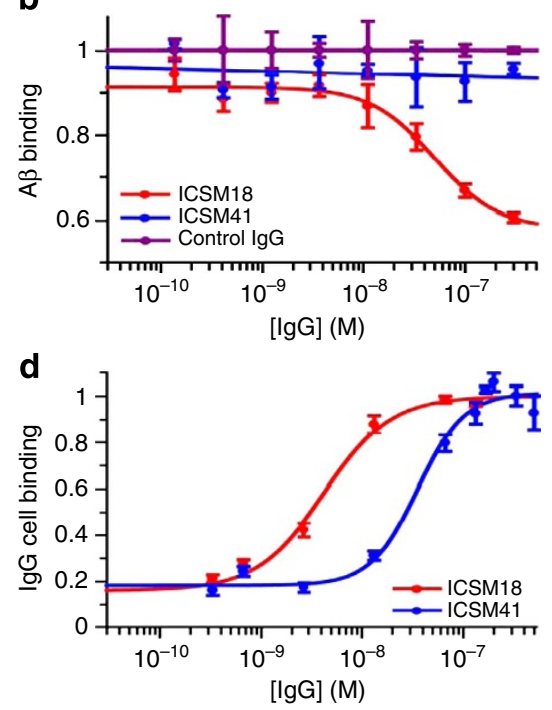

Figure 10 | Characterization of the interactions between $\mathbf{A} \boldsymbol{\beta}$ and $\mathbf{P r P C}$ and anti-PrPC antibodies. (a) Both $A \beta_{1-42}$ and biotinylated $A \beta_{1-42}$ protofibrils bind recombinant $\operatorname{PrPC}$ at low nanomolar concentrations $\left(n=3 \pm\right.$ s.e.m.). (b,c) Unlike ICSM18, ICSM41 did not prevent A $\beta_{1-42}$ protofibril binding to PrPC (b, $n=3 ; \mathbf{c}, n=9$, mean \pm s.e.m.). ${ }^{\star} P<0.05$ compared to control IgG (BRIC222), Kruskal-Wallis one-way ANOVA with Dunn's multiple comparison test. (d) FACS analysis revealed that ICSM18 bound to N2A cells, which express glycosylated mature PrPC, with an approximately eightfold higher affinity than ICSM41 ( $\mathrm{XC}_{50} 4 \pm 1 \mathrm{nM}$ and $33 \pm 7 \mathrm{nM}$, respectively, $n=4$, mean \pm s.e.m.).

dearth of studies of mAChR-dependent LTD in vivo may be owing to difficulties in optimizing suitable synaptic stimulation protocols. The present approach utilizes the insights gained from investigations of mAChR-dependent LTD in slices of cerebral cortex ${ }^{28}$. Currently used in vitro synaptic stimulation protocols to induce mAChR-dependent LTD at CA3-to-CA1 synapses have been reported to induce an LTD that is at least partly inhibited by $\mathrm{mAChR}$ antagonists ${ }^{19}$. The present finding that synaptic conditioning stimulation can induce LTD that is completely blocked by scopolamine provides strong evidence that mAChRdependent LTD that lasts for over $5 \mathrm{~h}$ can be induced by endogenously released $\mathrm{ACh}$ in vivo and therefore supports its proposed role in synaptic information storage.

Because previous reports had indicated that in vitro, $\mathrm{A} \beta$ strongly impairs $\mathrm{mAChR}$-mediated signalling ${ }^{29}$ that may underlie mAChR-dependent LTD in the cerebral cortex ${ }^{28}$, we predicted that mAChR-dependent LTD in the hippocampus would be inhibited by $A \beta$ in vivo. To our surprise, $A \beta$ enabled additional LTD while at the same time leaving a scopolamine sensitive component of LTD relatively unscathed. It was apparent that $A \beta$ usurped mAChR-dependent LTD by lowering the synaptic stimulation threshold to induce another form of LTD that was mAChR-independent. The mechanisms of the additional LTD, however, appear to be at least partly shared with mAChRdependent LTD, as the initial phase of the control LTD was partly occluded by the A $\beta$-enabled LTD.

Particularly surprising was the apparent lack of involvement of NMDARs in the facilitation of LTD by $A \beta$, especially in view of the presumed essential role of NMDARs in the relatively selective binding of $A \beta$ oligomers to synapses ${ }^{42}$. Moreover, antagonists of GluN2B subunits prevent $A \beta$-mediated facilitation of NMDAR-dependent LTD $^{5,6}$ and inhibition of NMDARdependent $\mathrm{LTP}^{12-15}$. These findings have led to the elucidation of a key role of GluN2B subunits in mediating the synaptic plasticity disrupting actions of $A \beta$ and have been extended to include many other deleterious effects of $A \beta^{40,43}$. However, based on the present results, targeting GluN2B is unlikely to prove to be an effective therapeutic strategy on its own and underlines the need to also explore non-NMDAR mechanisms.
Further undermining the putative primacy of NMDARs in the synaptic actions of $A \beta$ was the finding that $A \beta$ did not significantly affect NMDAR-dependent de-depression. This is all the more remarkable considering that $A \beta$ strongly inhibited NMDAR-dependent LTP at these same synapses using the same HFS induction protocol. Previous research has found that the persistent reversal of LTD by conditioning stimulation requires the recruitment of different signalling pathways to those usually necessary for LTP induction ${ }^{44,45}$. Thus the lack of inhibition of NMDAR-dependent de-depression at these synapses indicates that the inhibition of LTP by A $\beta$ is not due to the dependence of LTP on NMDARs. Furthermore, the present findings indicate that pharmacological inhibition of NMDARs may prevent potentially physiological reversal of LTD and leave any deleterious effects of A $\beta$-facilitated NMDAR-independent LTD unopposed.

The present findings underscore a much more central role for the mGlu5R in mediating the synaptic plasticity disrupting effects of $A \beta$ and suggest that the lowering of the threshold for LTD and inhibition of LTP are two sides of one coin. Our finding that $A \beta$ facilitated LTD, like A $\beta$-mediated inhibition of LTP, is blocked by antibodies that prevent $\mathrm{A} \beta$ binding to $\operatorname{PrP}^{\mathrm{C}}$ provides an explanation for the pivotal role of mGlu5Rs. Previous research ${ }^{46}$ has revealed that $A \beta$ acts as an extracellular scaffold to promote the inappropriate synaptic mobilization and activation of mGlu5R on cultured neurons. The membrane binding of $A \beta$ is prevented by both anti-mGlu5R and anti- $\mathrm{PrP}^{\mathrm{C}}$ antibodies in a non-additive manner ${ }^{46}$, consistent with the key role of $\operatorname{PrP}^{\mathrm{C}}$ in the binding of the $A \beta$ oligomer to plasmalemma ${ }^{25}$. The aberrant clustering of mGlu5R at synapses by $A \beta$ by binding to $\operatorname{PrP}^{\mathrm{C}}$ may trigger disruptive signalling activity that can enable LTD and inhibit LTP induction. Very recently direct evidence that $\operatorname{PrP}^{\mathrm{C}}$ mediates multiple effects of $A \beta$ oligomers, including dendritic spine loss in cultured neurons, by a direct physical linkage of $\mathrm{PrP}^{\mathrm{C}}$ with mGlu5Rs at or near the postsynaptic membrane was reported ${ }^{27}$. If the formation of $A \beta-\mathrm{PrP}^{\mathrm{C}}$-mGlu5R complexes is primary, then the requirement for NMDARs that contain GluN2B subunits in the inhibition of LTP by A $\beta$ is likely to be a downstream consequence. Indeed, mGlu5Rs provide a 
transduction link in the $\mathrm{A} \beta-\mathrm{PrP}^{\mathrm{C}}$ complex-mediated transmembrane coupling to NR2B subunits via activation of the tyrosine kinase $\mathrm{Fyn}^{27,40,47}$. In addition to $\mathrm{Fyn}$, an $\mathrm{A} \beta-\mathrm{PrP}^{\mathrm{C}}$ mGlu5R-mediated dysregulation of intracellular $\mathrm{Ca}^{2+}$, eukaryotic elongation factor 2 and $\mathrm{Arc}^{27}$ may contribute to synaptic plasticity disruption ${ }^{11}$ by $\mathrm{A} \beta$ in vivo.

Overall, the present research provides strong evidence that an $\mathrm{A} \beta-\mathrm{PrP} \mathrm{C}^{\mathrm{m}}$-m $\mathrm{Glu} 5 \mathrm{R}$ triad is critical for synaptic plasticity disruption, enabling an NMDAR-independent LTD to usurp mAChRdependent LTD and inhibit NMDAR-dependent LTP. Selectively targeting this $\mathrm{A} \beta-\mathrm{PrP}^{\mathrm{C}}$-mGlu5R triad offers many possible means of preventing dysfunction of critical brain plasticity mechanisms in early $\mathrm{AD}$.

\section{Methods}

Animals and surgery. Adult (250-350 g, 8-11 weeks old) male Wistar rats (BioResources Unit, Trinity College, Dublin) were used in all experiments. The animals were housed under a 12-h light-dark cycle at room temperature $\left(19-22^{\circ} \mathrm{C}\right)$. Before the surgery, animals were anesthetized with urethane (1.5-1.6 $\mathrm{g} \mathrm{kg}^{-1}$, i.p.). Lignocaine (10 $\mathrm{mg}, 1 \%$ adrenaline, subcutaneously) was injected over the area of the skull, where electrodes and screws were to be implanted. The body temperature of the rats was maintained at $37-38^{\circ} \mathrm{C}$ with a feedback-controlled heating blanket. The animal care and experimental protocol were approved by the Department of Health, Republic of Ireland.

Cannula implantation. In order to inject drugs or $\mathrm{A} \beta$ into the brain, a stainlesssteel cannula (22 gauge, $0.7 \mathrm{~mm}$ outer diameter) was implanted above the right lateral ventricle ( $1 \mathrm{~mm}$ lateral to the midline and $4 \mathrm{~mm}$ below the surface of the dura). i.c.v. injection was made via an internal cannula (28 gauge, $0.36 \mathrm{~mm}$ outer diameter). The solutions were injected in a $5 \mu \mathrm{l}$ volume over a 3 -min period or $10 \mu \mathrm{l}$ volume over a 6 -min period. Verification of the placement of cannula was performed post mortem by checking the spread of ink dye after i.c.v. injection.

Electrode implantation. Monopolar recording electrodes were constructed from Teflon-coated tungsten wires $(75 \mu \mathrm{m}$ inner core diameter, $112 \mu \mathrm{m}$ external diameter) and twisted bipolar stimulating electrodes were constructed from Tefloncoated tungsten wires $(50 \mu \mathrm{m}$ inner core diameter, $75 \mu \mathrm{m}$ external diameter) separately ${ }^{12}$. Field excitatory postsynaptic potentials (EPSPs) were recorded from the stratum radiatum in the CA1 area of the right hippocampus in response to stimulation of the ipsilateral Schaffer collateral-commissural pathway. Electrode implantation sites were identified using stereotaxic coordinates relative to bregma, with the recording site located $3.4 \mathrm{~mm}$ posterior to bregma and $2.5 \mathrm{~mm}$ lateral to midline, and stimulating site $4.2 \mathrm{~mm}$ posterior to bregma and $3.8 \mathrm{~mm}$ lateral to midline. In some animals, another stimulating electrode was implanted at a site located $2.5 \mathrm{~mm}$ posterior to bregma and $2.2 \mathrm{~mm}$ lateral to the midline. The final placement of electrodes was optimized by using electrophysiological criteria and confirmed via post-mortem analysis.

Electrophysiology. Test EPSPs were evoked by a single square-wave pulse $(0.2 \mathrm{~ms}$ duration) at a frequency of $0.033 \mathrm{~Hz}$ and an intensity that triggered a $50 \%$ maximum EPSP response. LTD was induced using $1 \mathrm{~Hz}$ LFS consisting of 900 pulses ( $0.2 \mathrm{~ms}$ duration). During the LFS the intensity was raised to trigger EPSPs of $95 \%$ maximum amplitude. A relatively weak LFS protocol, used to study the A $\beta$-mediated facilitation of LTD, consisted of 300 pulses $(0.2 \mathrm{~ms}$ duration) at $1 \mathrm{~Hz}$ with an intensity that evoked $95 \%$ maximum amplitude. LTP was induced using $200 \mathrm{~Hz}$ HFS consisting of one set of 10 trains of 20 pulses (inter-train interval of $2 \mathrm{~s}$ ). The stimulation intensity was raised to trigger EPSPs of $75 \%$ maximum during the HFS. None of the conditioning stimulation protocols elicited any detectible abnormal changes in background EEG, which was recorded from the hippocampus throughout the experiments.

Compounds and antibodies. Scopolamine (Sigma), mecamylamine (Sigma), (R,S)-3-(2-carboxypiperazin-4-yl)propyl-1-phosphonic acid (CPP, Ascent Scientific, Weston-Super-Mare, UK) and 3-((2-methyl-1,3-thiazol-4-yl)ethynyl)pyridine hydrochloride (MTEP hydrochloride, Ascent Scientific) were prepared in distilled water and diluted with saline to the required concentration. Pirenzepine (Ascent Scientific) was prepared in distilled water. $(\alpha \mathrm{R}, \beta S)-\alpha$-(4-hydroxyphenyl)- $\beta$-methyl4-(phenylmethyl)-1-piperidinepropanol hydrochloride (Ro 25-6981, Sigma) was dissolved in DMSO (dimethylsulphoxide) and diluted in saline. The following monoclonal antibodies, prepared in phosphate-buffered saline (PBS), were used in this study: 6D11 (Covance, \# SIG-39810); ICSM18, ICSM41 and BRIC222 (D-Gen, UK, \# ICSM18, ICSM41 and BRIC222)).

Synthetic A $\boldsymbol{\beta}$. We made two main different preparations of synthetic $A \beta$, soluble and protofibril $A \beta_{1-42}$. Our standard, soluble $A \beta_{1-42}$ (Bachem or Biopolymer
Laboratory, UCLA Medical School) was prepared as a stock solution of $64 \mu \mathrm{M}$ in mild alkali $(0.1 \%$ ammonium hydroxide) in milliQ water (Millipore Corporation, Ireland) to avoid isoelectric precipitation and then centrifuged at $100,000 \mathrm{~g}$ for $3 \mathrm{~h}$ to remove any fibril aggregates. An aliquot of the supernatant was taken to estimate peptide concentration using the micro BCA protein assay (Thermo-Fisher Scientific Life Science Research Products, Rockford, IL) and the remaining supernatant was stored at $-80^{\circ} \mathrm{C}$ until required. Whereas the test dose $(160 \mathrm{pmol})$ of soluble $\mathrm{A} \beta_{1-42}$ did not affect baseline transmission in the absence of LFS (see Results), double this dose $(320$ pmol, i.c.v. $)$ caused a small $(\sim 15 \%)$ decrease in baseline at $3 \mathrm{~h}$.

Differentially aggregated protofibril $A \beta_{1-42}$ and biotinylated $A \beta_{1-42}$ were synthesized, and purified by Dr James I. Elliott at Yale University (New Haven $\mathrm{CT})$. Peptide ( $\sim 10-20 \mathrm{mg}$ ) was weighed into a screw-cap 50-ml Sterilin tube, dissolved in anhydrous DMSO with gentle mixing for $2 \mathrm{~min}$ to produce a $5-\mathrm{mM}$ solution and then diluted to $100 \mu \mathrm{M}$ in phenol red-free Ham's F12 medium (Caisson Labs) and vortexed for $15 \mathrm{~s}$. Samples were aggregated without shaking for $48 \mathrm{~h}$, transferred to a $2-\mathrm{ml}$ eppendorf tube, centrifuged at $16,100 \mathrm{~g}$ for $20 \mathrm{~min}$ to remove any large preformed aggregates and the upper $90 \%$ for each solution collected, aliquoted, snap frozen in liquid $\mathrm{N}_{2}$ and stored at $-80^{\circ} \mathrm{C}$. Samples were then tested for the presence of large protofibrillar assemblies, known to bind avidly to $\operatorname{PrP}$ and cause PrP-dependent toxicity ${ }^{26}$. A $\beta_{1-42}$ protofibrils used for electrophysiology were further dialysed against $2 \times 5$ l of PBS in an 8000 MWCO semi-permeable membrane to ensure all DMSO and cell media were exchanged before freezing and characterization.

Electron microscopy. Five microlitre of peptide solution was applied to glowdischarged carbon-coated copper grids and left to bind for $60 \mathrm{~s}$. Excess solution was removed using grade 4 Whatman filter paper. Samples were negatively stained with $2 \%$ uranyl acetate for $30 \mathrm{~s}$, blotted then allowed to air dry. Images were acquired on an FEI Tecnai T10 electron microscope operating at $100 \mathrm{kV}$ and recorded on a $1 \mathrm{k} \times 1 \mathrm{k}$ charged couple device camera (Gatan) at a typical magnification of 34,000 with a pixel size of $5.03 \AA$.

SEC and multi-angle light scattering. Aliquots $(0.33 \mathrm{ml})$ of $\mathrm{A} \beta_{1-42}$ protofibrils were injected onto a Superdex 200 10/30 column (GE Healthcare) and eluted with PBS at a flow rate of $0.5 \mathrm{ml} \mathrm{min}^{-1}$ using an Agilent HPLC and peptide elution monitored by absorbance at $275 \mathrm{~nm}$. Light scattering was performed using a Wyatt DAWN HELEOS II multi-angle light scattering module with $\mathrm{A} \beta$ concentrations calculated using the refractive index.

TBS extract of human brain. $\mathrm{AD}$ brain 1 was obtained and used in accordance with the UCD Human Research Ethics Committee guidelines (under approval LS-E-10-10-Walsh). AD brain 2 was obtained and used in accordance with the Partner's Institutional Review Board (Walsh BWH 2011). In both cases informed consent was obtained from subjects. Samples of temporal cortex were obtained from $2 \mathrm{AD}$ cases referred to as $\mathrm{AD} 1$ and $\mathrm{AD} 2$. $\mathrm{AD} 1$ was from an 85-year-old male with dementia and fulminant amyloid and tangle pathology (Braak stage $=4)$ and was provided by Drs Dykoski and Cleary of Minneapolis VA Health Care System, and potently inhibits $\mathrm{LTP}^{48}$. $\mathrm{AD} 2$ was from an 81-year-old female who died with severe AD and was kindly provided by Dr Cindy Lemere of Brigham and Women's Hospital. Frozen cortex $(0.9 \mathrm{~g})$ was allowed to thaw on ice, chopped into small pieces and homogenized in $4.5 \mathrm{ml}$ of ice-cold $20 \mathrm{mM}$ Tris- $\mathrm{HCl}, \mathrm{pH} 7.4$, containing $150 \mathrm{mM} \mathrm{NaCl}$ with 25 strokes of a Dounce homogenizer (Fisher, Ottawa, Ontario, Canada $)^{31,48}$. Water-soluble $A \beta$ was separated from membrane-bound and plaque $\mathrm{A} \beta$ by centrifugation at $91,000 \mathrm{~g}$ and $4^{\circ} \mathrm{C}$ in a TLA 55 rotor (Beckman Coulter, Fullerton, CA, USA) for $78 \mathrm{~min}$. To eliminate bioactive small molecules the supernatant was exchanged into ammonium acetate. Thereafter, extracts were divided into two parts: one aliquot was immunodepleted of $A \beta$ by three rounds of 12 -h incubations with our anti-A $\beta$ antibody, AW8 (ref. 31), and protein A at $4{ }^{\circ} \mathrm{C}$. The second portion was not manipulated in any way and is simply referred to as $\mathrm{AD}$. Aliquots of samples were stored at $-80^{\circ} \mathrm{C}$ or used to assess $\mathrm{A} \beta$ content with a sensitive immunoprecipitation/western blot procedure. Our rabbit polyclonal antibody, AW8, was used (at a dilution of 1:80) for immunoprecipitation and a combination of the anti-A $\beta 40$ and $A \beta 42$ monoclonal antibodies, $2 \mathrm{G} 3$ and $21 \mathrm{~F} 12$ (each at $1 \mu \mathrm{g} \mathrm{ml}^{-1}$ ) for western blot. $A \beta$ concentration was estimated by reference to known quantities of synthetic $A \beta_{1-42}$. Antibodies $2 \mathrm{G} 3$ and $21 \mathrm{~F} 12$ were kindly provided by Drs P. Seubert and D. Schenk (Elan Pharmaceuticals).

A $\beta$-binding DELFIA. A $\beta$ binding to our recombinant $\operatorname{PrP}^{\mathrm{C}}$ (refs 26,37) was determined by an enzyme-linked immunosorbent assay (ELISA)-based protocol detected by the dissociation-enhanced lanthanide fluorescent immunoassay (DELFIA). Fifty microlitres of $1 \mu \mathrm{M}$ human huPrP ${ }_{23-231}$ (10 mM sodium carbonate, $\mathrm{pH}$ 9.6) was bound to medium binding 96-well white plates (Greiner) with shaking at 400 r.p.m. for $1 \mathrm{~h}$ at $37^{\circ} \mathrm{C}$, washed with $3 \times 300 \mu \mathrm{l}$ of PBS $(0.05 \%$ Tween-20), blocked with $300 \mu \mathrm{l}$ Superblock (Thermo Scientific) with shaking at 400 r.p.m. at $37^{\circ} \mathrm{C}$ for $1 \mathrm{~h}$ and washed with $3 \times 300 \mu \mathrm{l}$ of PBS $(0.05 \%$ Tween-20) Fifty microlitres of $\mathrm{A} \beta_{1-42}$ protofibrils were incubated in PBS (0.05\% Tween-20, $0.1 \%$ BSA) for $1 \mathrm{~h}$ at $25^{\circ} \mathrm{C}$ with shaking at 400 r.p.m. and washed with $3 \times 300 \mu \mathrm{l}$ of PBS (0.1\% Tween-20). A $\beta$ was detected using $50 \mu \mathrm{l}$ of $1 \mu \mathrm{g} \mathrm{ml}^{-1} 6 \mathrm{E} 10$ (Covance, 
\# SIG-39320) in DELFIA assay buffer (PerkinElmer) for $1 \mathrm{~h}$ at $25^{\circ} \mathrm{C}$ with shaking at 400 r.p.m., washed with $3 \times 300 \mu \mathrm{l}$ of PBS $(0.05 \%$ Tween-20) and incubated for $1 \mathrm{~h}$ at $25^{\circ} \mathrm{C}$ with shaking at 400 r.p.m. with $300 \mathrm{ng} \mathrm{ml}^{-1}$ of DELFIA Eu-N1 anti-mouse antibody in DELFIA assay buffer (PerkinElmer, \# 4002-0010), washed with $3 \times 300 \mu \mathrm{l}$ of PBS $(0.05 \%$ Tween-20) before enhancing with $100 \mu \mathrm{l}$ of DELFIA Enhancement Solution (PerkinElmer) ${ }^{49}$. Biotinylated $\mathrm{A} \beta_{1-42}$ protofibrils were detected using a 1:2,000 dilution of DELFIA Eu-N1 streptavidin (PerkinElmer, \# 1244-360), washed with $3 \times 300 \mu \mathrm{l}$ of PBS ( $0.05 \%$ Tween-20) before enhancing with $100 \mu \mathrm{l}$ of DELFIA Enhancement Solution (PerkinElmer, \# 4001-0010). Plates were scanned for time-resolved fluorescence intensity of the europium probe $\left(\lambda_{\mathrm{ex}}=320 \mathrm{~nm}, \lambda_{\mathrm{em}}=615 \mathrm{~nm}\right)$ using a PerkinElmer EnVision plate reader. Apparent $\mathrm{XC}_{50}$ values were calculated using a four-parameter $\mathrm{XC}_{50}$ curve with the maximum plateau signal for a given series used to define full occupancy.

\section{Anti-PrP antibody binding DELFIA. Fifty microlitres of $150 \mathrm{nM}$ of our} huPrP ${ }_{23-231}{ }^{26,37}$ (10 mM sodium carbonate, $\mathrm{pH}$ 9.6) was bound to high-binding 96-well white plates (Greiner) with shaking at 400 r.p.m. for $1 \mathrm{~h}$ at $37^{\circ} \mathrm{C}$, washed with $3 \times 300 \mu \mathrm{l}$ of PBS $(0.05 \%$ Tween-20), blocked with $300 \mu \mathrm{l}$ Superblock (Thermo Scientific) with shaking at 400 r.p.m. at $37^{\circ} \mathrm{C}$ for $1 \mathrm{~h}$ and washed with $3 \times 300 \mu \mathrm{l}$ of PBS $(0.05 \%$ Tween-20). Fifty microlitres of ICSM18 or ICSM41 (concentrationresponse curve, D-Gen, \# ICSM18 and ICSM41) were incubated in DELFIA assay buffer (PerkinElmer) for $1 \mathrm{~h}$ at $25^{\circ} \mathrm{C}$ with shaking at 400 r.p.m. and washed with $3 \times 300 \mu$ of PBS $(0.1 \%$ Tween-20). ICSM antibodies were detected by $50 \mu \mathrm{l}$ of $100 \mathrm{ng} \mathrm{ml}^{-1}$ of DELFIA Eu-N1 anti-mouse antibody (PerkinElmer, \# AD0207) in DELFIA assay buffer (PerkinElmer), washed with $3 \times 300 \mu$ lof PBS $(0.05 \%$ Tween-20) before enhancing with $100 \mu \mathrm{l}$ of DELFIA Enhancement Solution

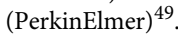

Anti-PrP antibody-mediated A $\beta$-inhibition DELFIA. Fifty microlitres of $1 \mu \mathrm{M}$ human huPrP $23-231$ (10 mM sodium carbonate, $\mathrm{pH}$ 9.6) was bound to mediumbinding 96-well white plates (Greiner) with shaking at 400 r.p.m. for $1 \mathrm{~h}$ at $37^{\circ} \mathrm{C}$, washed with $3 \times 300 \mu \mathrm{l}$ of PBS $(0.05 \%$ Tween-20), blocked with $300 \mu$ l Superblock (Thermo Scientific) with shaking at 400 r.p.m. at $37^{\circ} \mathrm{C}$ for $1 \mathrm{~h}$ and washed with $3 \times 300 \mu \mathrm{l}$ of PBS $(0.05 \%$ Tween-20). Fifty microlitres of ICSM18 or ICSM 41 $\left(1 \mu \mathrm{g} \mathrm{ml}^{-1}\right)$ were incubated in PBS $(0.05 \%$ Tween-20, $0.1 \%$ BSA $)$ for $1 \mathrm{~h}$ at $25^{\circ} \mathrm{C}$ with shaking at 400 r.p.m. and washed with $3 \times 300 \mu \mathrm{l}$ of PBS $(0.1 \%$ Tween-20). Biotinylated $\mathrm{A} \beta_{1-42}$ protofibrils were incubated in PBS ( $0.05 \%$ Tween- $20,0.1 \%$ BSA) for $30 \mathrm{~min}$ at $25^{\circ} \mathrm{C}$ with shaking at 400 r.p.m. and washed with $3 \times 300 \mu \mathrm{l}$ of PBS (0.1\% Tween-20). A $\beta$ was detected using a 1:2,000 dilution of DELFIA Eu-N1 streptavidin (PerkinElmer), washed with $3 \times 300 \mu$ l of PBS (0.05\% Tween-20) before enhancing with $100 \mu \mathrm{l}$ of DELFIA Enhancement Solution (PerkinElmer).

FACS. N2a cells (mouse neuroblastoma, ATCC) were harvested and washed with PBS, blocked with Fc $\gamma$ RIIb/CD16-2 $\left(1 \mu \mathrm{g} \mathrm{ml}^{-1}\right.$, \#18867, Santa Cruz) for $30 \mathrm{~min}$ at $4{ }^{\circ} \mathrm{C}$. Cells were incubated with different concentrations of ICSM18 or ICSM 41 antibodies (concentration response from $0.05-75 \mu \mathrm{g} \mathrm{ml}^{-1}$ ) for $45 \mathrm{~min}$ at $4{ }^{\circ} \mathrm{C}$. Subsequently, rinsed cells were stained with Alexa488- or FITC-conjugated antimouse antibodies $\left(2 \mu \mathrm{g} \mathrm{ml}^{-1}\right.$, \# A-11001 and \# F 2761, respectively, Invitrogen), fixed in $2 \%$ PFA for $10 \mathrm{~min}$ at $22^{\circ} \mathrm{C}$, stained with DAPI and kept at $4{ }^{\circ} \mathrm{C}$ until analysis. Samples were analysed on a CyAn ADP High Performance Flow Cytometer equipped with a $488 \mathrm{~nm}$ argon laser.

Data analysis. The magnitude of LTD is expressed as the percentage of pre-LFS baseline EPSP amplitude ( \pm s.e.m.). The sample size was chosen based on our knowledge of what is appropriate for in vivo electrophysiology to determine whether synaptic plasticity is induced or affected by $\mathrm{A} \beta$ or other interventions $s^{3,6,10,12}$. No data were excluded, and control experiments were interleaved randomly throughout. Two-tailed paired Student's $t$-tests (paired $t$ ) or one-way ANOVA with Tukey's multiple comparison test (one-way ANOVA-Tukey) were used to evaluate LTD within groups, and two-way ANOVAor unpaired Student's $t$-tests (unpaired $t$ ) were used to compare between groups. Kruskal-Wallis one-way ANOVA with Dunn's multiple comparison test was used to compare the effects of antibodies on $\mathrm{A} \beta$ binding to recombinant $\mathrm{PrP}^{\mathrm{C}}$. A $P<0.05$ was considered as statistically significant.

\section{References}

1. Selkoe, D. J., Mandelkow, E. \& Holtzman, D. M. (eds) The Biology of Alzheimer's Disease (Cold Spring Harbor Laboratory Press, 2012).

2. Palop, J. J. \& Mucke, L. Amyloid-beta-induced neuronal dysfunction in Alzheimer's disease: from synapses toward neural networks. Nat. Neurosci. 13, 812-818 (2010).

3. Cullen, W. K., Suh, Y. H., Anwyl, R. \& Rowan, M. J. Block of LTP in rat hippocampus in vivo by $\beta$-amyloid precursor protein fragments. Neuroreport $\mathbf{8}$, 3213-3217 (1997)

4. Lambert, M. P. et al. Diffusible, nonfibrillar ligands derived from A beta(1-42) are potent central nervous system neurotoxins. Proc. Natl Acad. Sci. USA 95, 6448-6453 (1998).
5. Li, S. et al. Soluble oligomers of amyloid beta protein facilitate hippocampal long-term depression by disrupting neuronal glutamate uptake. Neuron 62, 788-801 (2009).

6. Kim, J. H., Anwyl, R., Suh, Y. H., Djamgoz, M. B. \& Rowan, M. J. Usedependent effects of amyloidogenic fragments of (beta)-amyloid precursor protein on synaptic plasticity in rat hippocampus in vivo. J. Neurosci. 21, 1327-1333 (2001).

7. Collingridge, G. L. et al. The NMDA receptor as a target for cognitive enhancement. Neuropharmacology 64, 13-26 (2013).

8. Shankar, G. M. et al. Amyloid-beta protein dimers isolated directly from Alzheimer's brains impair synaptic plasticity and memory. Nat. Med. 14, 837-842 (2008).

9. Cleary, J. P. et al. Natural oligomers of the amyloid-beta protein specifically disrupt cognitive function. Nat. Neurosci. 8, 79-84 (2005).

10. Wong, T. P. et al. Hippocampal long-term depression mediates acute stressinduced spatial memory retrieval impairment. Proc. Natl Acad. Sci. USA 104, 11471-11476 (2007).

11. Collingridge, G. L., Peineau, S., Howland, J. G. \& Wang, Y. T. Long-term depression in the CNS. Nat. Rev. Neurosci. 11, 459-473 (2010).

12. Hu, N. W., Klyubin, I., Anwyl, R. \& Rowan, M. J. GluN2B subunit-containing NMDA receptor antagonists prevent Abeta-mediated synaptic plasticity disruption in vivo. Proc. Natl Acad. Sci. USA 106, 20504-20509 (2009).

13. Li, S. et al. Soluble Abeta oligomers inhibit long-term potentiation through a mechanism involving excessive activation of extrasynaptic NR2B-containing NMDA receptors. J. Neurosci. 31, 6627-6638 (2011).

14. Rammes, G., Hasenjager, A., Sroka-Saidi, K., Deussing, J. M. \& Parsons, C. G. Therapeutic significance of NR2B-containing NMDA receptors and mGluR5 metabotropic glutamate receptors in mediating the synaptotoxic effects of beta-amyloid oligomers on long-term potentiation (LTP) in murine hippocampal slices. Neuropharmacology 60, 982-990 (2011).

15. Ronicke, R. et al. Early neuronal dysfunction by amyloid beta oligomers depends on activation of NR2B-containing NMDA receptors. Neurobiol. Aging 32, 2219-2228 (2011).

16. Gu, Z. \& Yakel, J. L. Timing-dependent septal cholinergic induction of dynamic hippocampal synaptic plasticity. Neuron 71, 155-165 (2011).

17. Wang, Q., Rowan, M. J. \& Anwyl, R. Beta-amyloid-mediated inhibition of NMDA receptor-dependent long-term potentiation induction involves activation of microglia and stimulation of inducible nitric oxide synthase and superoxide. J. Neurosci. 24, 6049-6056 (2004).

18. Bolshakov, V. Y., Carboni, L., Cobb, M. H., Siegelbaum, S. A. \& Belardetti, F. Dual MAP kinase pathways mediate opposing forms of long-term plasticity at CA3-CA1 synapses. Nat. Neurosci. 3, 1107-1112 (2000).

19. Volk, L. J., Pfeiffer, B. E., Gibson, J. R. \& Huber, K. M. Multiple Gq-coupled receptors converge on a common protein synthesis-dependent long-term depression that is affected in fragile $\mathrm{X}$ syndrome mental retardation. J. Neurosci. 27, 11624-11634 (2007).

20. Jo, J. et al. Muscarinic receptors induce LTD of NMDAR EPSCs via a mechanism involving hippocalcin, AP2 and PSD-95. Nat. Neurosci. 13, 1216-1224 (2010).

21. Warburton, E. C. et al. Cholinergic neurotransmission is essential for perirhinal cortical plasticity and recognition memory. Neuron 38, 987-996 (2003).

22. Lee, H. K., Min, S. S., Gallagher, M. \& Kirkwood, A. NMDA receptorindependent long-term depression correlates with successful aging in rats. Nat. Neurosci. 8, 1657-1659 (2005)

23. Thathiah, A. \& De Strooper, B. The role of G protein-coupled receptors in the pathology of Alzheimer's disease. Nat. Rev. Neurosci. 12, 73-87 (2011).

24. Fisher, A. Cholinergic modulation of amyloid precursor protein processing with emphasis on M1 muscarinic receptor: perspectives and challenges in treatment of Alzheimer's disease. J. Neurochem. 120(Suppl 1), 22-33 (2012).

25. Lauren, J., Gimbel, D. A., Nygaard, H. B., Gilbert, J. W. \& Strittmatter, S. M. Cellular prion protein mediates impairment of synaptic plasticity by amyloidbeta oligomers. Nature 457, 1128-1132 (2009).

26. Nicoll, A. J. et al. Amyloid-beta nanotubes are associated with prion proteindependent synaptotoxicity. Nat. Commun. 4, 2416 (2013).

27. Um, J. W. et al. Metabotropic glutamate receptor 5 is a coreceptor for Alzheimer abeta oligomer bound to cellular prion protein. Neuron 79, 887-902 (2013).

28. Caruana, D. A., Warburton, E. C. \& Bashir, Z. I. Induction of activitydependent LTD requires muscarinic receptor activation in medial prefrontal cortex. J. Neurosci. 31, 18464-18478 (2011).

29. Kelly, J. F. et al. Amyloid beta-peptide disrupts carbachol-induced muscarinic cholinergic signal transduction in cortical neurons. Proc. Natl Acad. Sci. USA 93, 6753-6758 (1996).

30. Hu, N. W., Smith, I. M., Walsh, D. M. \& Rowan, M. J. Soluble amyloid-beta peptides potently disrupt hippocampal synaptic plasticity in the absence of cerebrovascular dysfunction in vivo. Brain 131, 2414-2424 (2008).

31. Mc Donald, J. M. et al. The presence of sodium dodecyl sulphate-stable Abeta dimers is strongly associated with Alzheimer-type dementia. Brain 133, 1328-1341 (2010). 
32. Doyle, C., Holscher, C., Rowan, M. J. \& Anwyl, R. The selective neuronal NO synthase inhibitor 7-nitro-indazole blocks both long-term potentiation and depotentiation of field EPSPs in rat hippocampal CA1 in vivo. J. Neurosci. 16, 418-424 (1996).

33. Mony, L., Kew, J. N., Gunthorpe, M. J. \& Paoletti, P. Allosteric modulators of NR2B-containing NMDA receptors: molecular mechanisms and therapeutic potential. Br. J. Pharmacol. 157, 1301-1317 (2009).

34. Montgomery, J. M. \& Madison, D. V. Discrete synaptic states define a major mechanism of synapse plasticity. Trends Neurosci. 27, 744-750 (2004).

35. Abraham, W. C., Mason-Parker, S. E., Irvine, G. I., Logan, B. \& Gill, A. I Induction and activity-dependent reversal of persistent LTP and LTD in lateral perforant path synapses in vivo. Neurobiol. Learn. Mem. 86, 82-90 (2006).

36. Wang, Q., Walsh, D. M., Rowan, M. J., Selkoe, D. J. \& Anwyl, R. Block of long-term potentiation by naturally secreted and synthetic amyloid betapeptide in hippocampal slices is mediated via activation of the kinases c-Jun N-terminal kinase, cyclin-dependent kinase 5, and p38 mitogen-activated protein kinase as well as metabotropic glutamate receptor type 5. J. Neurosci. 24, 3370-3378 (2004).

37. Freir, D. B. et al. Interaction between prion protein and toxic $A ß$ assemblies can be therapeutically targeted at multiple sites. Nat. Commun. 2, 336 (2011).

38. Beringue, V. et al. PrPSc binding antibodies are potent inhibitors of prion replication in cell lines. J. Biol. Chem. 279, 39671-39676 (2004).

39. Khalili-Shirazi, A. et al. Beta-PrP form of human prion protein stimulates production of monoclonal antibodies to epitope 91-110 that recognise native PrPSc. Biochim. Biophys. Acta 1774, 1438-1450 (2007).

40. Um, J. W. et al. Alzheimer amyloid-beta oligomer bound to postsynaptic prion protein activates Fyn to impair neurons. Nat. Neurosci. 15, 1227-1235 (2012).

41. Larson, M. et al. The complex $\operatorname{PrP}(\mathrm{c})$-Fyn couples human oligomeric Abeta with pathological tau changes in Alzheimer's disease. J. Neurosci. 32, 16857-16871a (2012).

42. De Felice, F. G. et al. Abeta oligomers induce neuronal oxidative stress through an N-methyl-D-aspartate receptor-dependent mechanism that is blocked by the Alzheimer drug memantine. J. Biol. Chem. 282, 11590-11601 (2007).

43. Kessels, H. W., Nabavi, S. \& Malinow, R. Metabotropic NMDA receptor function is required for beta-amyloid-induced synaptic depression. Proc. Natl Acad. Sci. USA 110, 4033-4038 (2013).

44. Daw, M. I. et al. PDZ proteins interacting with C-terminal GluR2/3 are involved in a PKC-dependent regulation of AMPA receptors at hippocampal synapses. Neuron 28, 873-886 (2000).

45. Lee, H. K., Barbarosie, M., Kameyama, K., Bear, M. F. \& Huganir, R. L. Regulation of distinct AMPA receptor phosphorylation sites during bidirectional synaptic plasticity. Nature 405, 955-959 (2000).

46. Renner, M. et al. Deleterious effects of amyloid beta oligomers acting as an extracellular scaffold for mGluR5. Neuron 66, 739-754 (2010).
47. Beraldo, F. H. et al. Metabotropic glutamate receptors transduce signals for neurite outgrowth after binding of the prion protein to laminin gammal chain. FASEB J. 25, 265-279 (2011).

48. O’Nuallain, B. et al. A monoclonal antibody against synthetic Abeta dimer assemblies neutralizes brain-derived synaptic plasticity-disrupting Abeta. J. Neurochem. 119, 189-201 (2011).

49. Soini, E. \& Kojola, H. Time-resolved fluorometer for lanthanide chelates-a new generation of nonisotopic immunoassays. Clin. Chem. 29, 65-68 (1983)

\section{Acknowledgements}

We wish to thank C. Lemere and M. Farrell for providing the AD brain samples, H. Saibil, W. Cullen, T. Ondrejcak and I. Klyubin for technical advice and A. Billinton for helpful discussions during the design of these experiments. This work was supported by the Science Foundation Ireland, the Health Research Board of Ireland and the European Union Seventh Framework Programme 528 (Grant Agreement MEMOLOAD 201159) to M.J.R., a grant from an anonymous foundation to D.M.W. and the Medical Research Council UK to J.C.

\section{Author contributions}

N.-W.H. and M.J.R. conceived the study; N.-W.H., A.J.N., D.M.W. and M.J.R. designed the research; N.-W.H. and D.Z. performed and analysed electrophysiology experiments; A.J.N. prepared the differentially aggregated A $\beta$ and characterized it and the ICSM antibodies A.J.M. isolated and characterized human brain extracts; T.O'M. characterized the standard soluble $A \beta_{1-42}$ preparation; S.A.P. performed FACS experiments; C.T. performed EM analysis; N.-W.H., A.J.N., J.C., D.M.W. and M.J.R. wrote the paper.

\section{Additional information}

Competing financial interests: D.M.W. is a member of the scientific advisory board of CogRx and Alzinova as well as a consultant to Eisai Co. J.C. is a director and shareholder of D-Gen Limited, an academic spin-out company in the field of prion diagnosis, decontamination and therapeutics. The remaining authors declare no competing financial interests.

Reprints and permission information is available online at http://npg.nature.com/ reprintsandpermissions/

How to cite this article: $\mathrm{Hu}, \mathrm{N} .-\mathrm{W}$. et al. mGlu5 receptors and cellular prion protein mediate amyloid- $\beta$-facilitated synaptic long-term depression in vivo. Nat. Commun. 5:3374 doi: 10.1038/ncomms4374 (2014).

(c) (i) This work is licensed under a Creative Commons Attribution 3.0 cc Unported License. The images or other third party material in this article are included in the article's Creative Commons license, unless indicated otherwise in the credit line; if the material is not included under the Creative Commons license, users will need to obtain permission from the license holder to reproduce the material. To view a copy of this license, visit http://creativecommons.org/licenses/by/3.0/ 